\title{
دلالة صورة الطفل في الرسم العراقي المعاصر
}

\author{
م.د. قاسم جليل مهدي/ كالية الهنوز الجميلة / جامعة واسط \\ م.م. اممد نور كاظم/ كاية الفنوز الجميلة / جامعة بابل

يتضمن البحث دراسـة ( دلالة صـورة الطفل في الرسم العراقي المعاصر)، اذ شـل اربعة فصول ، الفصل الاول يشـل مشكلة البحث واهميته والحاجة اليه ، وهدف البحث وحدوده والمصطلحات الواردة فيه ، امـا الفصل الثاني يتضمن مبحثين ، المبحث الاول التعبير الدلالي للصورة ، و المبحث الثاني الروئية التاريخية للرسم العراقي المعاصر ، وتضمن الفصل الثالث على اجراءات البحث ، مجتمع البحث وعينة

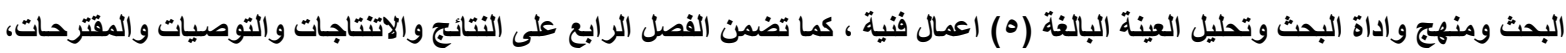
ومن اهم النتاج التي توصل اليها الباحث : تجسدت صورة الطقل في المنجز التشكيلي العراقي من خلال تثـغيل المنظومـة التخيلية للقنان، اذ

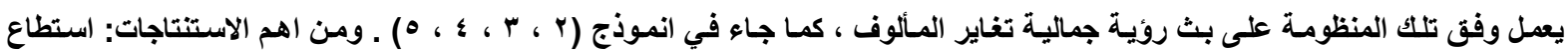
الفنان العراقي المعاصر الاهتمام بصورة الطفل عبر توثيق موضوعات ترتبط بالاحداث الواقعية والمشاهد الحياتية المتعددة.

\section{Summary}

The study includes (Significance of the image of the child in contemporary Iraqi painting), The first chapter included the problem of research, its importance and the need for it, the purpose of the research and its limits and the terminology contained therein. The second chapter includes two topics, the first is the semantic expression of the picture, the second is the historical vision For the contemporary Iraqi painting, and the third chapter contains the research procedures, the research society, the research sample, the methodology and the research tool and the analysis of the sample $\left({ }^{\circ}\right)$ works of art, and the fourth chapter contains the results, conclusions, recommendations and proposals, and the most important product reached by the researcher: The image of the child embodied in the Iraqi plastic art through the operation of the imaginary system of the artist, as it works according to that system to broadcast the aesthetic vision of the variance of the familiar, as in the model $(r, r, \varepsilon, \bullet)$. One of the most important conclusions: The contemporary Iraqi artist was able to take care of the child's image by documenting topics related to real events and multiple life scenes.

\section{الفصل الاول}

اولا: مشكلة البحث: إن المتتبع لنشأة الفن يلحظ مـا ور اء دوافع الإنتاج الفني من قوى ذاتيـة واقتصـادية ودينيـة وسياسية وثقافية ، هذه القوى من شأنها أن تستثير الفنان فيعمل على تمثيلها بطرق عدة تختلف من وقت لآخر وكأنها في دوامة من التحوّ لات. و الفنـان عندما ينجز أي منجز فني إنمـا يضـعه في صورة يطرح من خلالها مشناعره وأفكاره و عاداته وتقاليده. بحيث نشمل هذه الصورة رؤيوية الثكل المرئي ، فضـلا عن دلالات متعددة متحولة من فترة إلى أخرى مـع تطور امكانـات الفنـان وقدرته العقلية و النفسية والتخيليـة المختلفة جر اء تأثره بظروف البيئة المحيطة من خوف وحزن وفرح وأحلام وتأملات ومختلف الوسـائل الاتصـالية. و عندما يعكس الفن في الغالب الواقع الخـارجي للمحيط والبيئة فهو يعيد إنتاج الظواهر الطبيعيـة، والصـر اعات الاجتماعيـة و الحالة الاقتصادية، و التشكيلات الثقافية، من خلال نتاجاته المتباينـة و المعتمدة على المنظومـة التخيليـة، اذ بعبر عن دور تربوي خاص به عندما تكون مهمته توجيه رسائل تربوية وإرشادية للمتلقي ، ويمتص صدمات نفوره وتمرده على و اقعه ليتيح له مزيداً من احتمالات التكيف مع مجتمعه الخاص، في تقلباتهه وتغير اته وابتعاده عن 
سكونيته المتوارثـة مـن أنظمـة اجتماعيـة وتاريخيـة سـالفة . وكذللك فـان للفن موقفـاً خاصـاً بـه مـن هذا الواقع الموضوعي حين يكثف عن المخفي لهذا الواقع بحيث يتيح إمكانية رفض هذا الظاهرة أو تلك ، أو الدفاع عنها و العمل على ترسيخها وتثمينها بعد أن يتم إخر اجها للعلن و إثنهار ها أمام الجمهور بقوة الفن ووظيفته الخلاقة ('). كما يعد الفن وسيلة من وسائل الاتصال الإنساني، ويتميز فن التصوير باعتباره أكثر المجالات الفنية مباشرة في في وتئي الحوار وفي سرعة توصيل مضمونه. كما انه الفن الوحيد الذي يتخطى عنصر الزمن. بمعنى إن نظرة واحدة

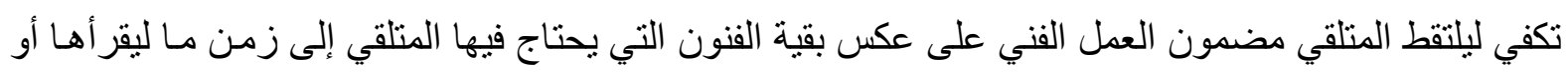

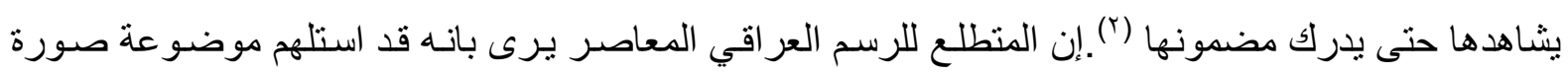
الطفل في الرسم وتعددت دلالاتها الرمزية ـ من هنا وجد الباحثنان ضرورة التعرف على آليات اشتغال صورة الطفل في فن الرسم وما تحمله من دلالات ـ هذا الخطاب يجده الباحثان قد اثار العديد من التسـاؤلات عن اهمية وهنة صورة الطفل في الرسم ، وكيفية اشتغاله في الفن ؟ .

ثانيـا : أهميـة البحث والحاجـة اليـه: يستمد البحث الحسالي أهميته من أهميـة مشكلته الناثـئة عن الحاجـة الىى الكثف عن دلالات صورة الطفل في الرسم العر اقي المعاصر وان التصدي لهذه المشكلة قد يلبي حاجة الباحثين

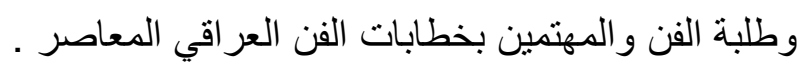
ثالثا : هدف البحث: يهدف البحث الحالي الى : كثف دلالة صورة الطفل في الرسم العر اقي المعاصر . رابعا: حدود البحث: يتحدد البحث الحالي بدراسـة دلالة صورة الطفل في الرسم العر اقي المعاصـر للمدة من

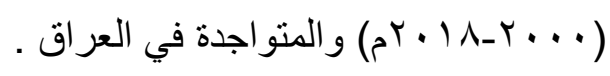

$$
\begin{aligned}
& \text { خامسا : تحديد مصطلحات البحث }
\end{aligned}
$$

الدلالة لغة : الدلالة هي المعنى و البرهان و الإرشاد. فقد اتفق عليها لغويا بأنها: (signification)

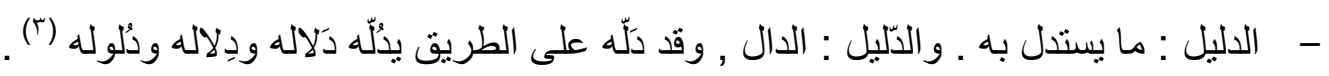

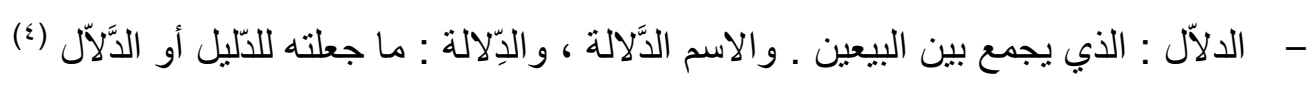

و هناك تطابق بين كلاً من ألفاظ الدلالة و المعنى والمضمون و المحتوى. فالمعنى هو المضمون ، والمضمون هو المحتوى (0). و إن كلاً من هذه الألفاظ تؤدي وظيفة من واطئ واحدة وهي الدلالة.

الدلالة اصطلاحا : عرّفها الجرجـاني بأنها " كون الثـيء بحالـة يلزم من العلم بـه العلم بشيء آخر, و الثـيء

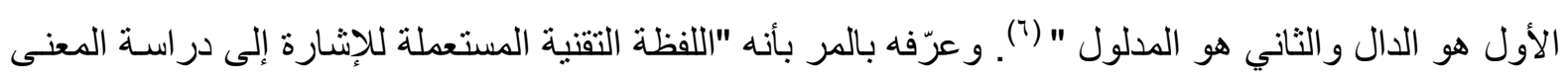

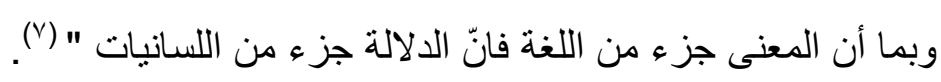
الدلالة إجر ائياً: المعنى الذي تتتجهـ صـورة الطفل شكلا ومضمونا في الرسم العر اقي وفق الرؤيـة المعالجاتيـة و التقنية و الاسلوبية للفنان.

الصورة (IMAGE) لغة: صَوَّر تصوير ا، صورهُ، جعل لله صورة وشكلا، صورهُ، رسمةُ، صورهُ، نقشهُه(^). 
اصطلاحاً: تطلق على ما يرسم المصور بالقلم ، وآلة التصوير ، أو على ارتسام خيال الثيء على المرآة أو في الذهن أو على ذكرى الثـيء المحسوس الغائب عن الحس (9). كمـا وردت في (معجم المصطلحات الأدبيـة

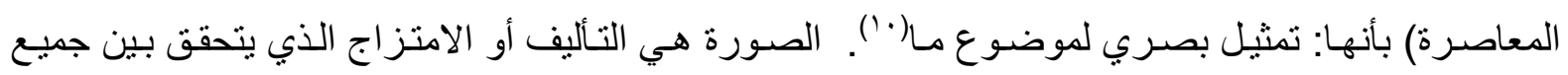

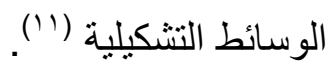

الصـورة اجر ائيا: رسم الفنان لموضوع مـا أو تسجيل هذا الموضوع بآلـة الكامير ا أو حضسور الموضوع في الذهن ، وهي هيئة متكاملة تنتج من جميع الوسائط التشكيلية ، وبذلك تصبح الصـورة الفنية تشكيلاً ذا موضوع يرتبط بالطفل شكلا ومضمونا في الرسم العر اقي المعاصر.

الفصل الثاني

المبحث الاول : التعبير الدلالي للصورة

إن الدراسة الموضوعية للفن يجب أن تنظر إلى العمل الفني على إنـه علامـة واللوحة يجب أن تحمل دلالـة ويجب أن تشكّل علامة في ضوء موضو عها وطريقتها، وفي و اقعتها وقصدها (r') ـ وفي الفن تتضح الدلالة

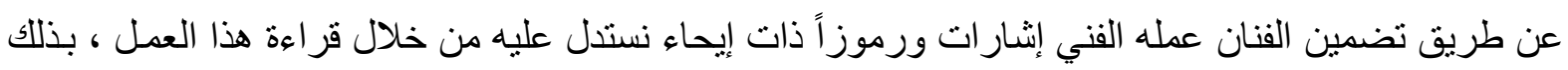
فإن ما يتحكم بمعرفة هذه الدلالات من جانبنا ـ كمتلقيّن ـ هو أمـا أن نكون عـارفين بمدلو لات هذه الدوال ، بمعنى إننا نعرف أشكالاً ذات علاقة بأشكال تدل عليها، أو إن هذه الأشكال المتضمنة في العمل الفني تطابق هون أشتياء معروفة ومتداولة، ومن هنـا فالفن هو المكان الأكثر خصوبة نحو مثنل هذا المفهوم و اتسـاعه ومن ثم الم الإبحار فيه. ولقد حدد (سوسير) بأن العلامة وحدة ثنائية المبنى تتكون من دال ومدلول، وإن سلسلة الأصوات، هي الدال و التي تستدعي في ذهن المستمع صورة ذهنية هي المدلول(با') ـ ووفقاً للتقسيم الذي قدمـه (سوسير)

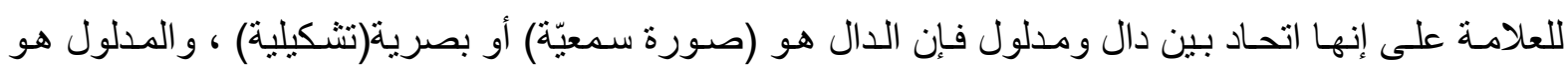
(تصوّر) ذهني غير مادي، وفي أغلب الأحيان ، تكون الرابطة التي تجمع الدال بالمدلول اعنباطية ـ فهي لا لا

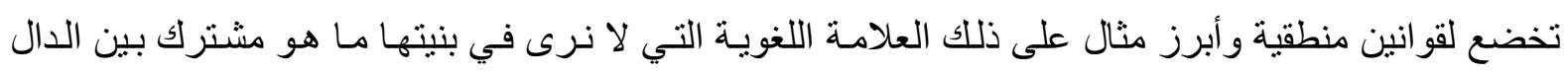

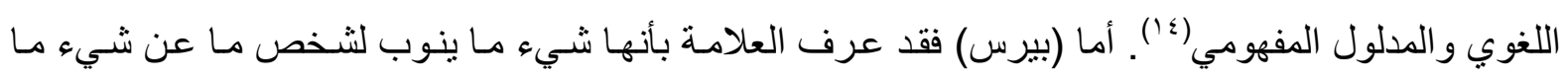

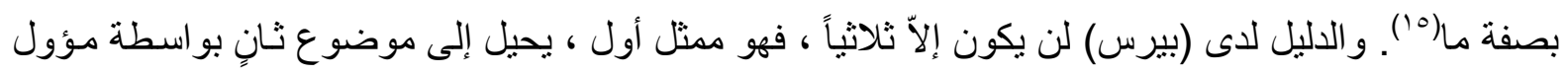

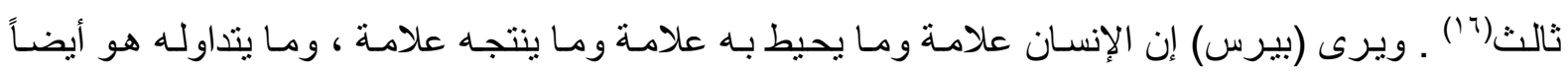

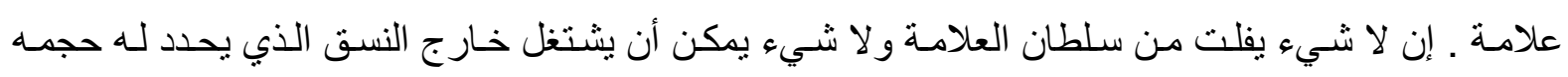

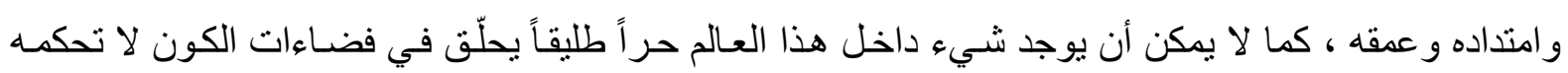

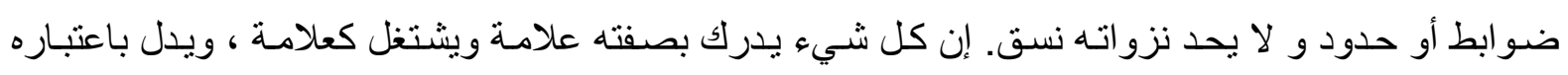
علامـة. فالتجربـة الإنسـانية بـداء من صـرخة الرضيع إلى تأمل الفيلسوف ليسـت سوى سلسـلة مـن العلامـات

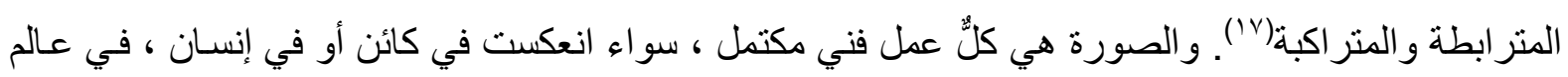
مـا أو في عمل أو في رمز أو استعارة أو في ملحمـة. وإن مقدماتها كانت قد تشكلت قبل ظهور هـا بالمدلول الاصطلاحي الذي عرفت به بزمن طويل، مثلما تشكلت الملامح و المعاني الجمالية في العمل الانسـاني اليومي 
الذي يمارسـه في حياتهـ العاديـة قبل أن يخطر لـه الفن بمسـائله المختلفة مهمـا كانت بسيطة ، فليس من بـاب الفي المصادفة على الإطلاق أن تجد معالم ثقافة ما قبل التاريخ وذلك الاهتمام وذلك الفهم لدى الإنسان اليوم و لا سيما

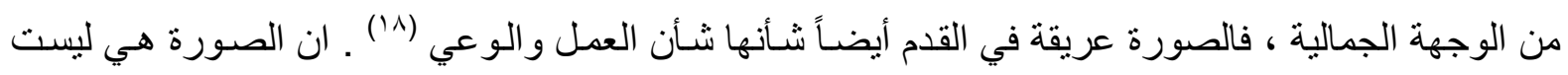
الثكل الخارجي بثلاثة أبعاد (طول و عرض وارتفاع مثلما يفهم هندسياً) بل هي تعين المادة الأولى وخصائصها

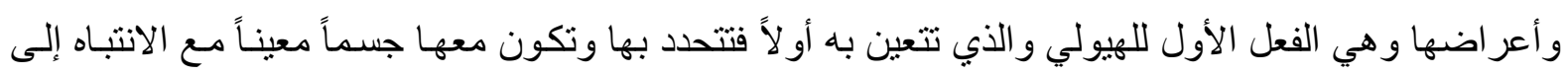
أن الهيولي و الصورة ليسا جو هرين تامين متجاورين في الجسم فلو كانا كذللك لأمكن تفسير هما لوحدهما ولذلك

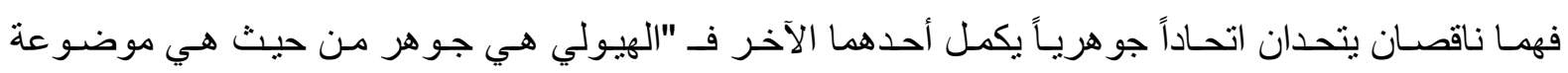

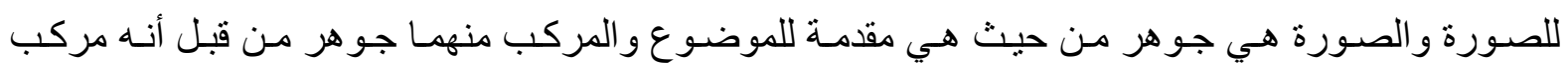

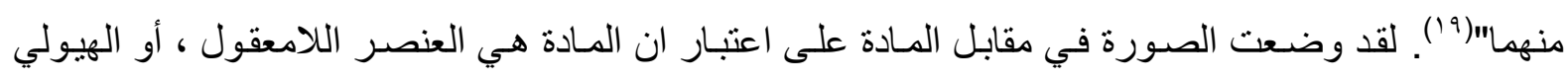
المهوشة المتقلبة بطبيعتها، التي تجىء الصورة فتطبعها بطابعها الخاص.. لذلك اعتبرت الصورة أزليـة أبديـة، على حين اعتبرت المادة متغيرة متبدلة(·r). إذ يقصد بالمادة ما يستعمل في صنع شيء، أو ما يدخل في تركيبه

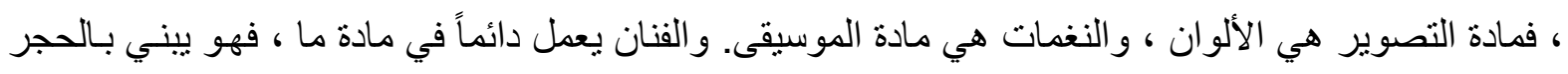

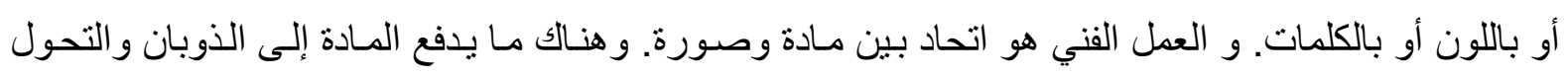

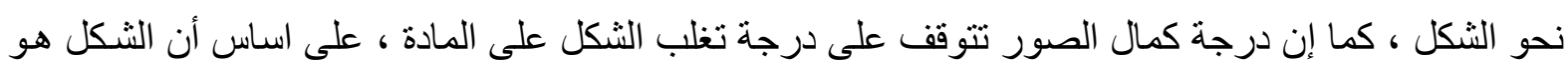

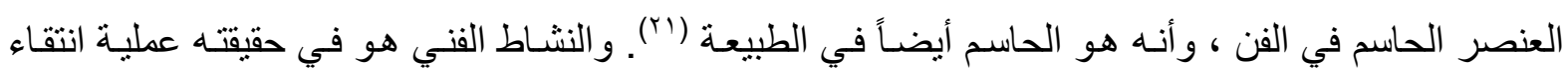
وتتظيم لمادة مستمدة من الطبيعة أو من الحياة الانسانية ، فقد تكون المادة التي يفرض عليها الفنان صورة معينة

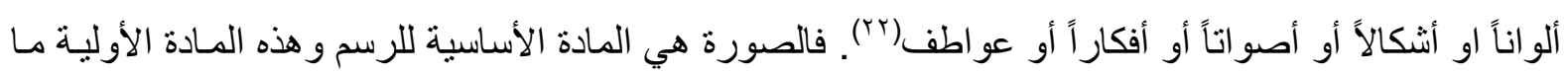

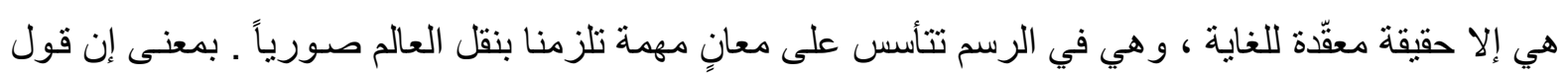
الرسم هو قول بصري إذ تتحول وسائل الإدر الك والتخيّل و المعرفة مجتمعة إلى صورة ثم تتحول هذه الصسورة

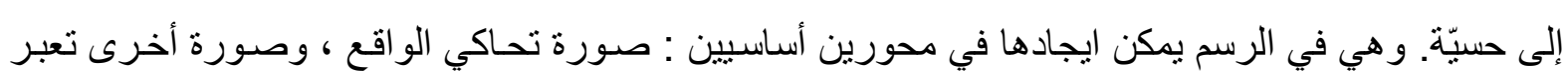

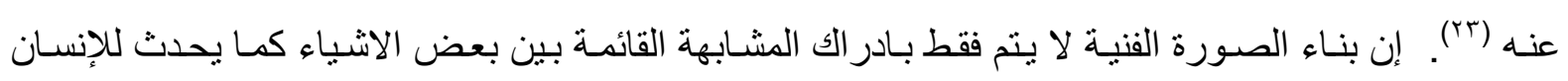

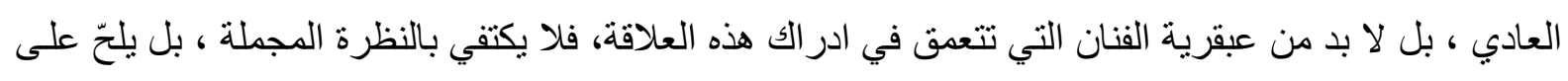

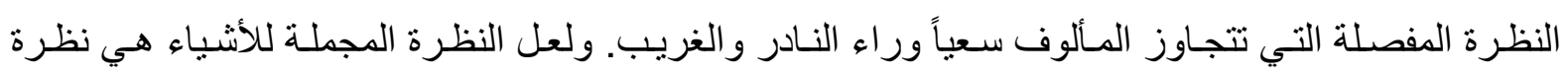
الإنسان العادي التي غالباً ما تتسم بالبلادة والاهمال ، في حين إن النظرة المفصلة هي نظرة الإنسان الفنان التي ولي

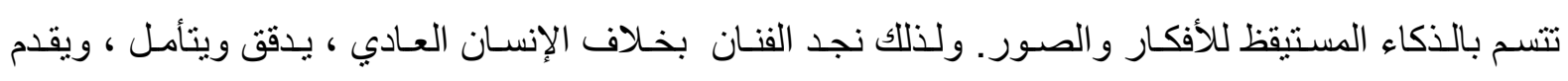

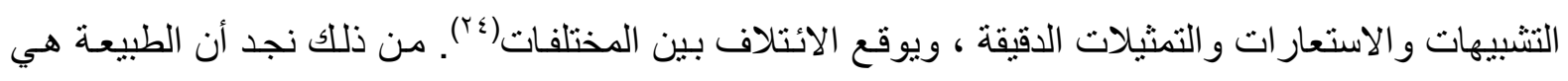
الصورة الأوسع والأشمل في الوجود ومن خلالها يستقي الانسان كل ما يخطر في ذهنه من إثارة اتجاهها. و هي مشكّلة بقدرة مبدع وهو الله (جل جلاله). فالصورة هي نتاج لفعل واع. و على المستوى الفني يقوم الفنان باعـادة

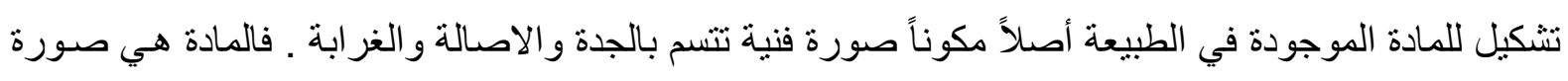

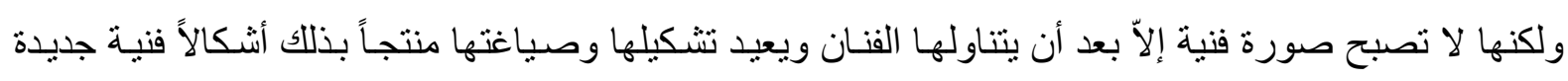
ذات دلالات متعددة. فتصبح الصورة الفنية هي الصياغة التشكيلية الخاصة أو المتفردة التي ينتقيها الفنان المبدع 
من سـائر الصياغات لتمثيل المعاني أو الدلالات المختلفة. و الصـورة الفنيـة في الرسم هي العمل الفني الذي

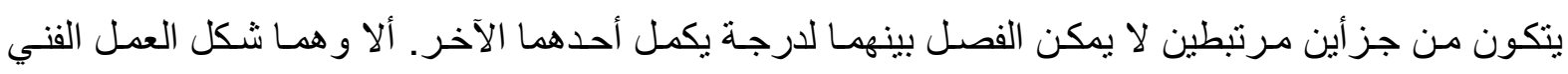
ودلالته والصورة الفنية طريقة خاصة من طرق التعبير أو وجه من أوجه الدلالة ، تتحصر أهميتها في ما تحدثه

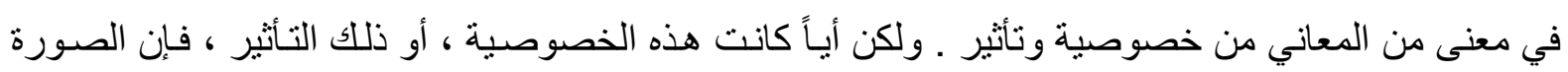

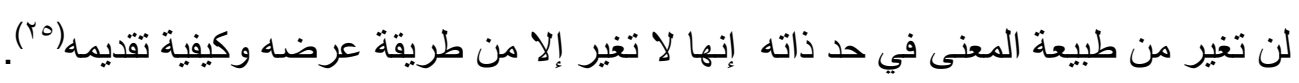
إن المضمون يأتي نتاجا لكيفية معالجة الثكل والموضوع المطروح معا، ومن هنـا فـان المضمون ليس مـا يقدمه الفنان، بل ايضا كيف يقدمه، في أي سياق وباي درجة من الوعي الاجتمـاعي والفردي، وبكيفيـة امتلاكه

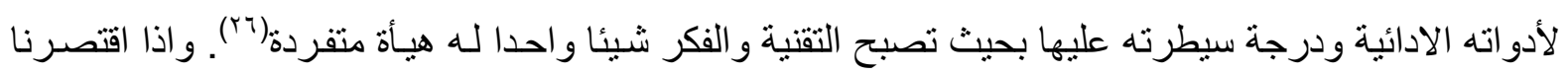
على اعتبار المعنى مسألة ارتبـاط وايحاء فأننا بذلك سوف نشوه حقيقة الصورة. و والو اقع ان الكيفيات الحسية

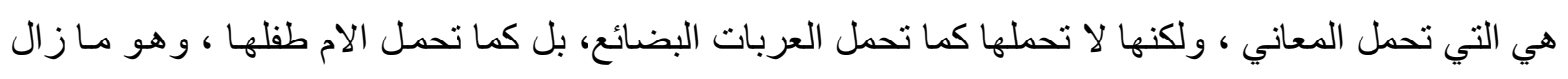

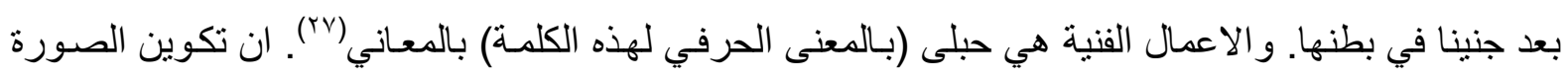

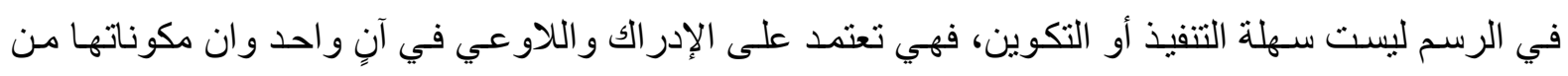

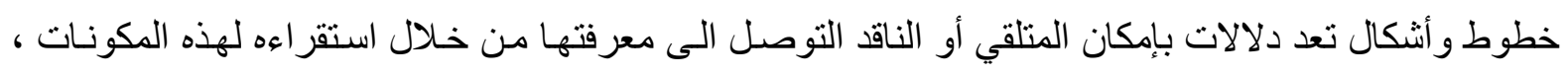

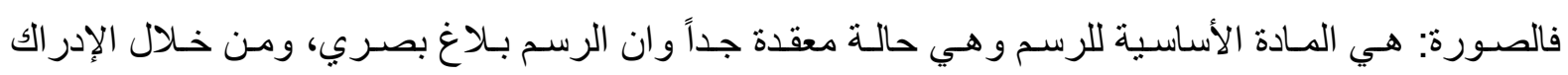

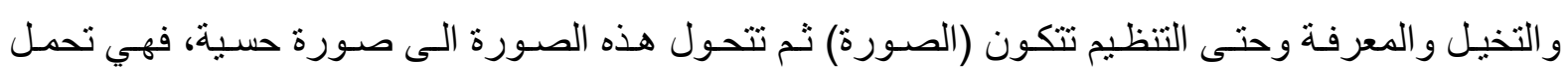

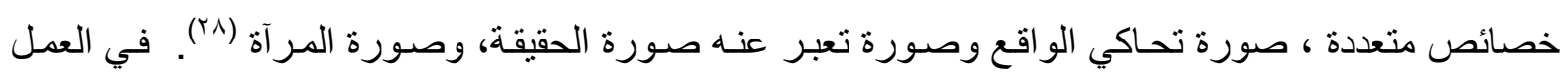
الفني يظهر الثكل و المضمون في حالة تلاحم غير منفصم ، وفي وحدة تجمعهما معا سواء كان هذا العمل فنيا

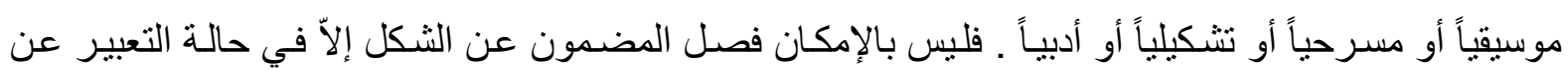

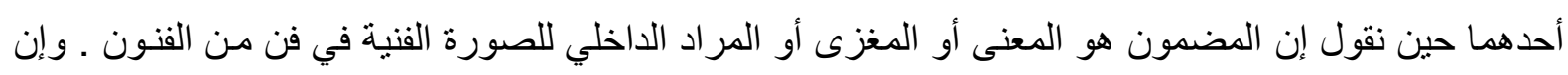
الثكل هو التركيبة المادية أو البناء الثكلي الذي يحد المعنى الداخلي إطـاره أو سياجه ، في محافظة منـه على الثى

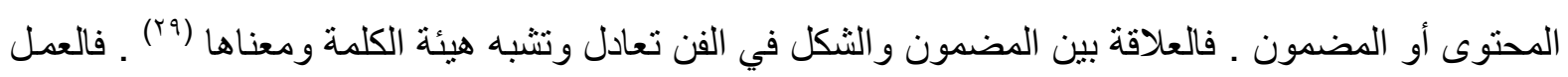
الفني يتضمن مضموناً معيناً هو خلاصة ما يعبر عنه أو يتضمنه العمل الفني من خيال ومشاعر وفكرة فقد يعبر

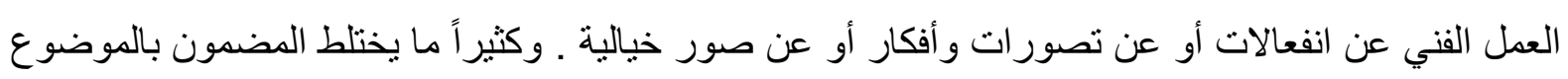
في العمل الفني ، لكن من الواضح أن الموضوع هو شيء يقع خارج العمل الفني ، ومع ذلك فالعمل الفني يشير بـاله

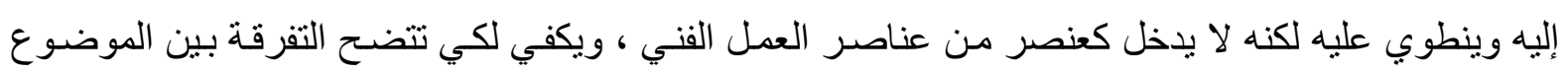

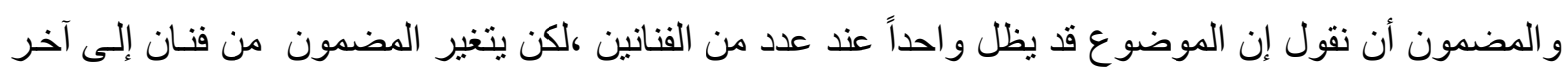
حسب رؤيته و انفعاله بالموضوع. فكم في التصوير و الثـعر من روائع فنيـه قد اتخذت من الحرب و السـلام

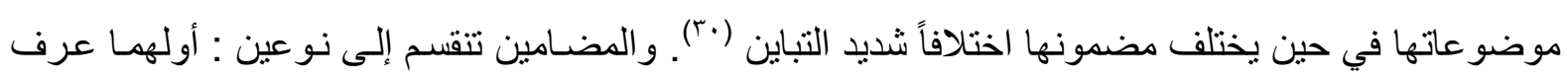

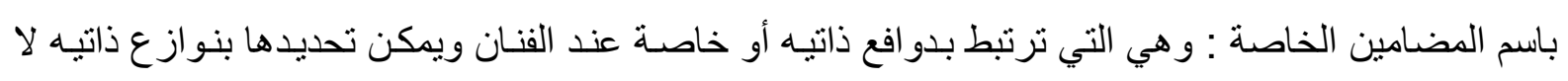

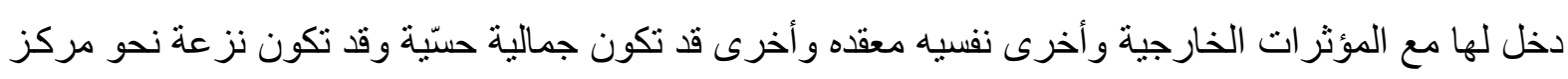

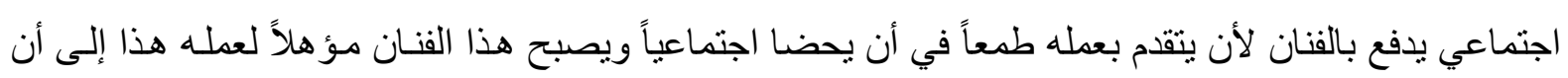


ينال مركزاً مرموقاً يطمع فيه .أمـا النوع الثاني من المضـامين فعرف باسم المضـامين العامـة ومنبعها الدوافع العامة التي تهيمن على حِّ الفنان وتمتلك فكرهِ وقد تتوزع بين دو افع اجتماعيه بقصد معالجـة الحياة اليوميـة

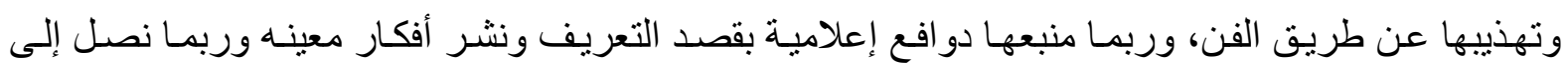

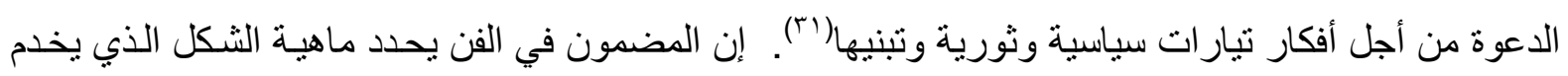
الأفكار الكامنة فيه .و الثكل الذي يقع عليه الاختيار لا يصل منفرداً ، ولا يظهر من اجل نفسه ،بقدر مـا يكون تجسيداً وتعبير اً وأداة إيصـال موظّفة توظيفاً فنيـاً مفيداً. على هذا نستطيع أن نضـع أيدينا على مهمـة الثـكل الخطيرة في مجال الفن ، فبدونها لا يستطيع المضمون أن يتفتح أو يتنفس أو يعثر على حياة له ، وبالتالي يعجز

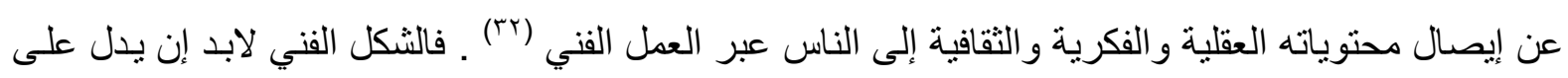
شيء ويشير إلى شيء ويقول شيئاً . على أن يقول ويشير ويدل بالثكل وفي الثكل . ونقول بالثكل وفي الثكل لأن الثكل ، ببساطة ، هو وحده ما يقوى على إحداث الانفعال الاستطيقي و غيره لا يحدث إلاّ انفعالات الحياة . فالثكل هو كل شيء في العمل الفني، الثكل هو المضمون في حضوره الاستطيقي ـ و الثكل الدال هو الثكل

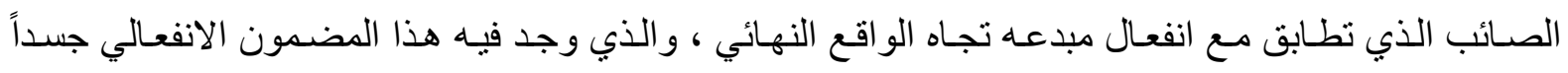
للمثول الموضوعي ومنفذاً إلى الذوات الأخرى(rّ). ومن ذللك نجد ان صورة الطفل في اللوحة هي عبارة عن كن شكل حامل للمعنى، و هذا الأخير بدوره يثير معاني أخرى متعددة . ونحن نستدل على صـورة الطفل من خـلال الثكل البصري الذي ينتجـه الفنان بفعل التعبير الداخلي. لذا يرى الباحثان ان صورة الطفل في العمل الفني تحمل دلالات تعبر عن انعكاسـات واقعيـة يعيشـها الفنـان ضمن مجتمعه، اذ يحساول من خلالها نقل صورة لـه وتقوده في الوقت ذاته الى المضي في عالم مليء بالرموز والاشارات و الدلالات متعددة المعاني .

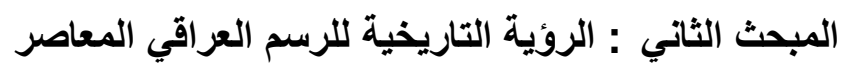

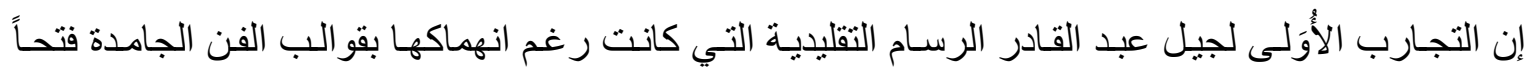
للذاكرة العر اقية التي ظلت في سبات يمتد من سبعة قرون خلت تحت حكم متخلف(؟ّ) ـ وتتجلى ملامح البداية التي تمثل تأسيساً لفن الرسم في العراق بطابعها المحاكي للبيئة العر اقيـة معتمدة على الاتجاه الواقعي في بنـاء اللوحة وتوزيع عناصر ها التشكيلية ، ورغم ان هذا الجيل مـارس الفن كهوايـة لا احتر اف الا انه ارسى قاعدة فنية لها اهميتها التاريخية ودور ها الايجابي كموروث يسر الطريق لمن لحقهم وكبداية اتصسال ثقافي مهم لوعي

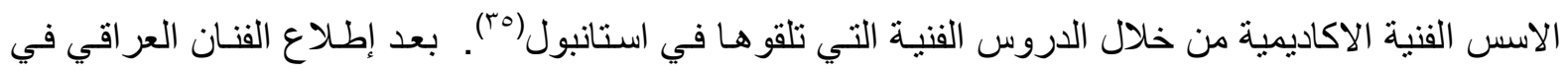
العقد الثلاثيني من القرن العشرين على المدارس الأوربية وما فيها من نتاج فني، كان لذلك انعكاس على تطوره في الحياة الفنية " إذ أنه مع بداية النصف الثاني من القرن العشرين ، اتضـح ان مصير العمل الفني في العراق

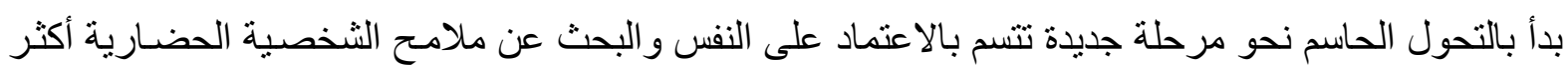

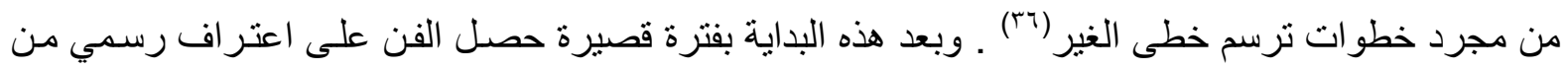

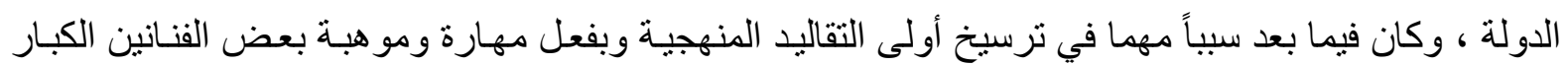
أخذت المهار ات الفنيـة تتجذر بنتائج متقدمة ، فظهرت في التجارب الجماعيـة أولا، إذ نوالت الجمعيات الفنية بالظهور نتيجة رغبة الفنانين العر اقيين في جعل أفكار هم متطابقة مع نواياهم ففي مطلع • ـ9 1 تأسست (جمعية 
أصدقاء الفن)(*) والتي كانت رغم اختفائها بعد سنوات قليلة من أفق الفن العر اقي لها أهميتها في ربط أواصر الألفة وتوحيد الجهود بين الفنانين العر اقيين الرواد(Yَّ).ان انتشار الوعي السياسي في فترة الأربعينيات ، كان لها

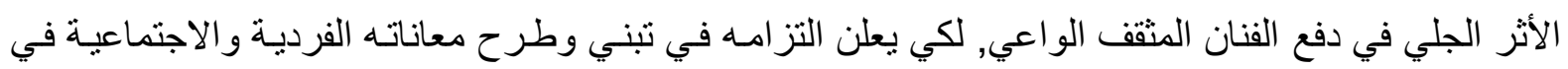

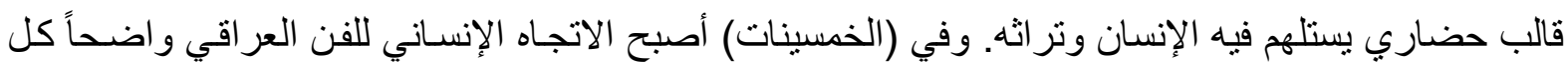
الوضوح، وذلك بعد ان اتضحت وظيفة الفن الاجتماعي، وقد شجعت على ذلك ظروف مـا بعد الحرب العالميـة

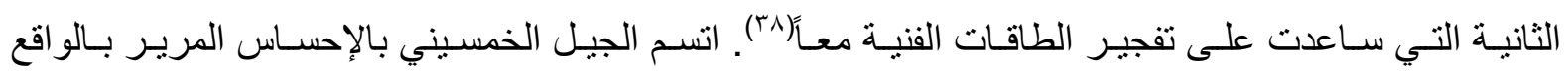

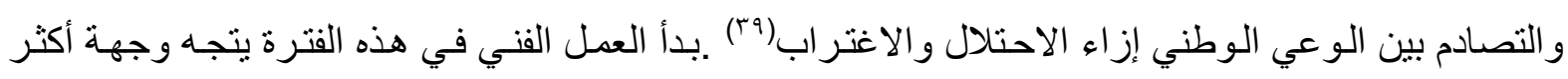
حداثة , ذلك إن الاهتمام والحرص على اكتشاف الوسائل الفنية الأكثر معاصرة كانت تمثل الصيخ الاجتماعية و الاقتصادية والثقافية الأكثر جدوى في تحقيق الملامسح (التقدمية) و(الحضـارية) معاً لثقافة الإنسـان العراقي . كما استطاعت (الحرب العالمية الثانية) ان تتجح في تعميق شعور الإنسـان بإنسـانيته عن طريق أحكام تعريف

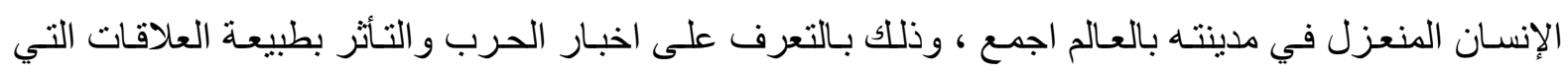

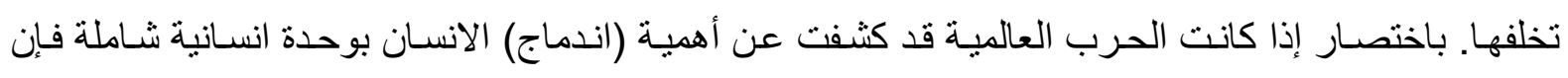
سنوات ما بعد الحرب كثفت عن ضرورة (تعرف) نفس هذا الانسان على مقومات شخصيته واستقلالها، وهكذا فان ظهور(جماعة الرواد ـ 90 (1) (*) كجماعة فنية جاء معبرا عن موقف جديد اقترن بالدعوة إلى الرسم بأسـاليب

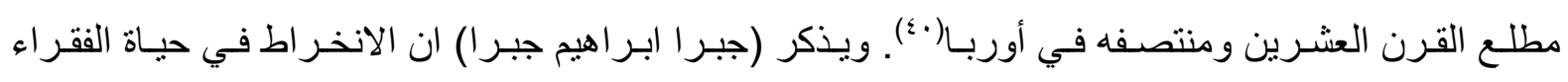
و المعدمين كان في الواقع الصفة المميزة للكثير من النتاج الفني العر اقي في أو ائل الخمسينيات و أوسطها , ولعل

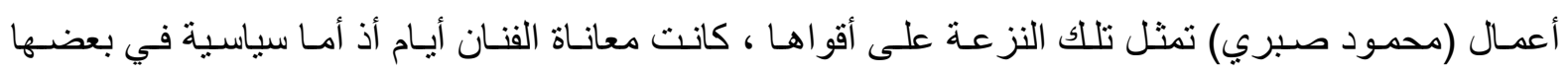

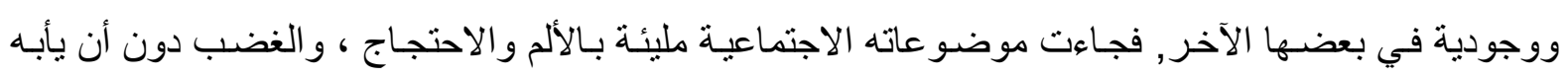
كثير القضايا الأسلوب و التراث التي كانت تشغل بال الفنانين الآخرين( (\&).

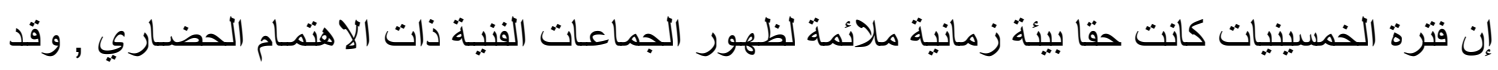
تمثل ذلك بـ(جماعة بغداد للفن الحديث (901 (1)) , فقد شهد الو اقع التقافي في هذه الفترة علاقة صميميه تنشـأ ما بين الفنان العر اقي كمثقف وكائن اجتماعي , أقبل على الفن الحديث بشكل حاسم , وعن التزام انساني , وبين

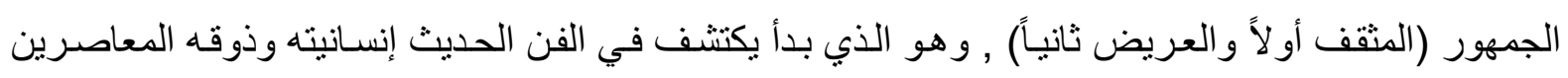

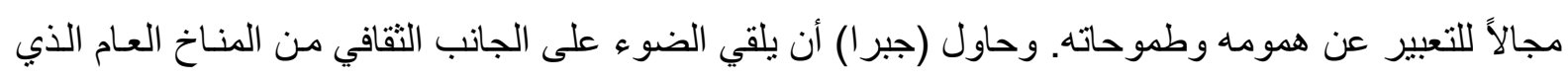
نشأت فيه (جماعة بغداد للفن الحديث) انه مناخ ملائم لتعميق الثعور الإنساني بالحضـارة ومن منطلقات فكريـة معاصـرة , فليس عبثا أن يسود الثـعور بـالفكر الإنسـاني عبر (الفلسفة الوجوديـة) وبالثـعور الاجتمـاعي عبر الإنر الفلسفة المادية إلى الحد الذي يتحقق بشكل رؤية فنية ذات ارتباط بـالتراث (r\&) ـ وتضمن العقد الستيني انعطافاً مهما في تاريخ الحركة التشكيلية العراقية , مما ادى إلى زيادة عدد التجمعات الفنية وتنوع الأسـاليب التي بدأت بالظهور والاختفاء , وتميزت بعض هذه التجمعات بأفكار هم الجريئة وأسـالييهم الجديدة و أطلقت للفنان حريـة

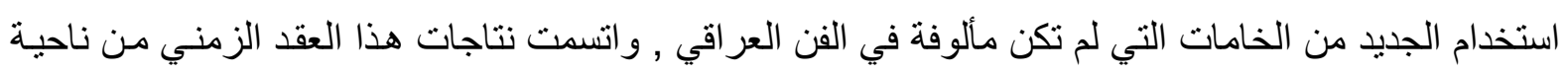
مادة الموضوع باهتمامات عديدة في المشكلات الحضارية التي ارتبطت بإطار هـا الوطني او القومي والإنسـي وني 
وتعددت وتتو عت معالجتها الثنائعة بغنى دلالات أفكار ها (rآ) ـلقد عاش الفنان في هذه المرحلة تناقضـا بيناً بين

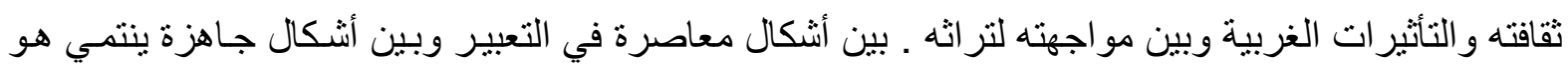

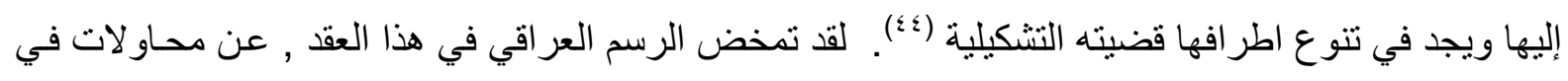
إعادة النظر في رسومات الخمسينيين, و العمل على تخفيف وطأة التشخيص و إبداء الاهتمـام بمشكلات السطح التصويري و الفكر الإنساني على وفق منظور تحرري , تكريساً لمفهوم الفرديـة في الرسم , وقد ظهرت أبـان

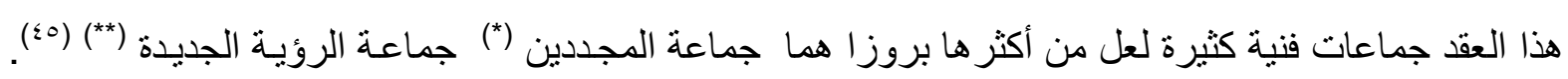

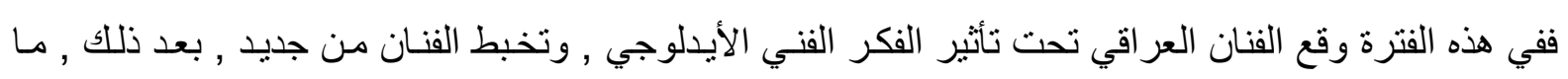
بين التعبير الوظيفي (تكريس الثكل للمضمون) و التعبير الحر ( تكريس المضمون للشكل) (جأ) ـ وفي منتصف الستينيات , كان للعامل السياسي أثره في الأعمال الفنية, لكن هذا الأثر لم يظهر بنفس الثكل السـابق , بل تجلى لئى

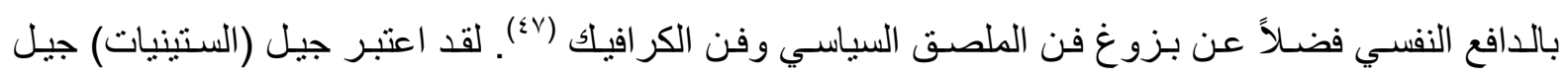

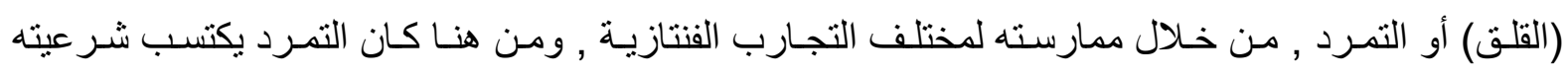
الإبداعية ووحدته في التعبير , ولهذا السبب ظهرت تجارب عديدة للفنانين ولكن قلق هذا الجيل يحمل إخلاصـه

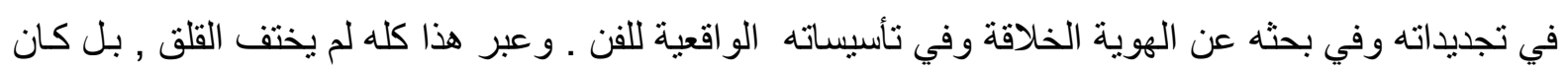

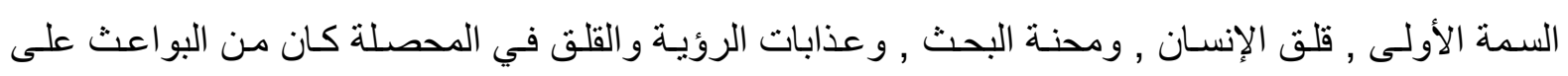

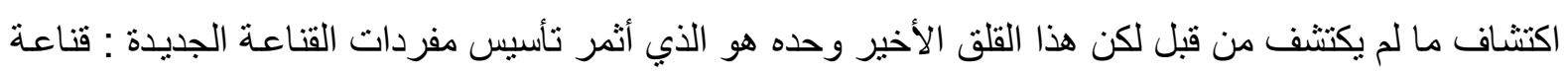

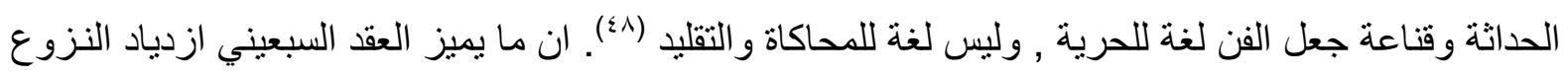
نحو مجالات الحداثة و التجديد المتواصل باتجاه خلق سطح تصويري بأثكال جديدة , و التعبير بالأفكار ذات

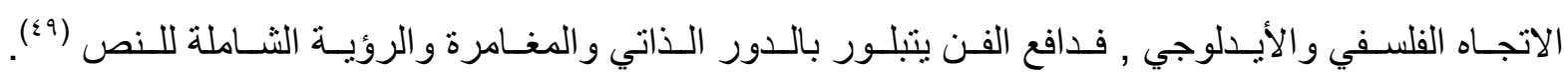

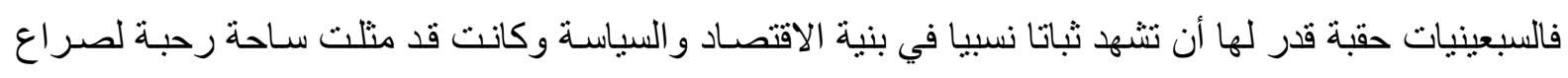
حام بين منجزات الفنانين (الخمسينين) و (الستينين) فيما انحسرت خصوصية العقد على المستوى الفردي , مــا جعل منه عقداً رخواً بوصف عام (.0). كان عقد السبعينيات عقد نضـ ولم يكن عقد و لادة , في السبعينيات شهدت (بغداد) قيام أهم معارض الرسم الثخصية في تاريخها المعاصر ـ وكان ذلك يجري في ظل تعدديـة في النظريات والمفاهيم الفنية , كانت هذه التعدديـة تقف ور اءء و لادة العديد من الجماعات الفنيـة التي أقيم معظمها على أساس قاعدة اكتشفت في الستينيات مادتها الأساسية تكمن في أن ليس بإمكان العالمي أن بلغي الوطني بلـ بإمكانه أن يثريه ويزيده صلابة (10). لقد أسهم نمو الوعي الفكري لدى الفنان إلى رسم معالم أو ملامح جديدة

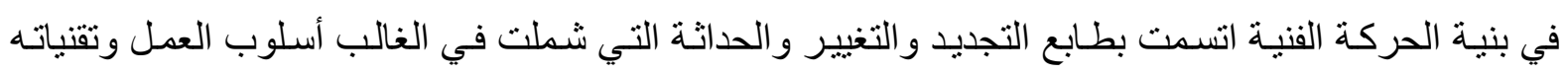

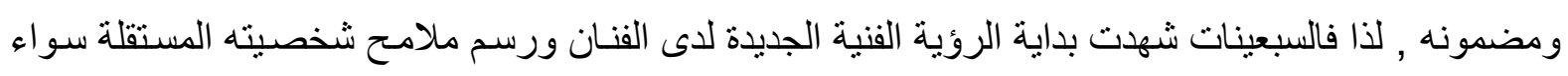
ضمن العمل الفردي أو الجماعي , وتوسعت تجربـة الفنـان وازداد النزوع نحو الحداثـة والتجديد ولكن باتجـاه تأصيل رؤيته في الفن ومنحه قيمة إنسانية خاصة, بالتعبير عن أفكاره وفلسفته بصورة متقدمة و إبداعية ليس في مجال الرسم فقط بل حتى في مجال التظظير و الدر اسات النقدية كانعكاس حتمي لارتباط الفنـان بـالو اقع وتحو لاتهـ

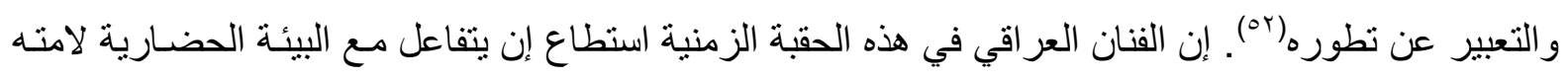


فهو حتى وان بلـغ تخومـا تجريدية عالية طبقا للمنظور الغربي , الا انهـ دائم القلق ازاء مسألة الحضـارة التي يعيش ضمنها , فالطابع التجريبي للرسم في هذا العقد يتضح من خـلال المعانـاة التي واجهت الفنان باكتشـافاته المثيرة بجماليتها .

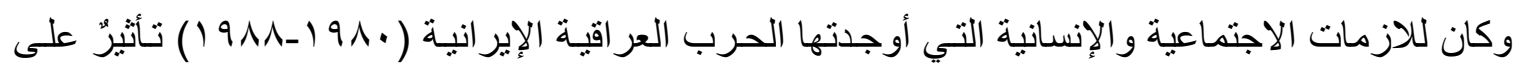

ذات الفنان بوصفه مشارك فعلي في هذه الحرب ، فثمة متغيرات في مفهوم الفن و اللوحة فمن حيث المضمون

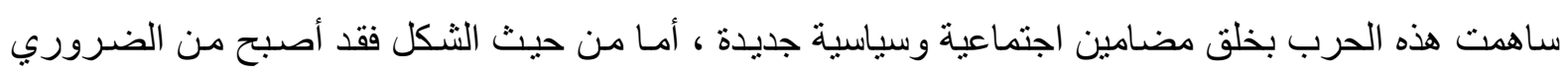

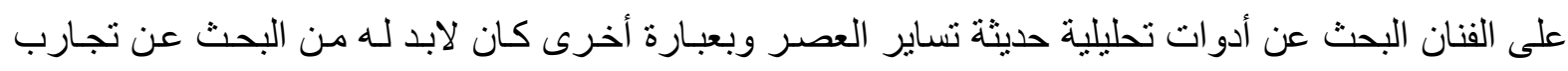
جديدة تستطيع احتو اء التجربة المعاثة مما انتهى بهم إلى فهم فضاء الحداثة بوصفها هذه المرة هدفا على أسـاس

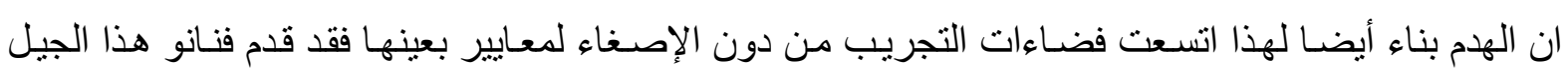
تجارب تنطوي على التجربة الثخصية بوسائل تقنية غير تقليدية تضعهم في طليعة فناني الحداثة ومـا بعدها في

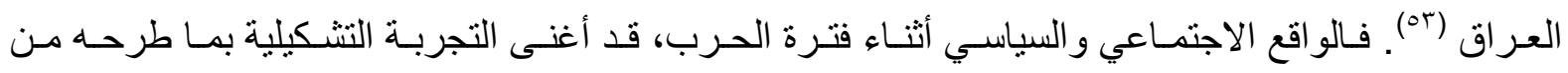
تساؤلات لامست الرؤية الفنية والجانب الفكري بخلق مضامين اجنماعية وسياسية جديدة لهذا الو اقع ، أمـا من

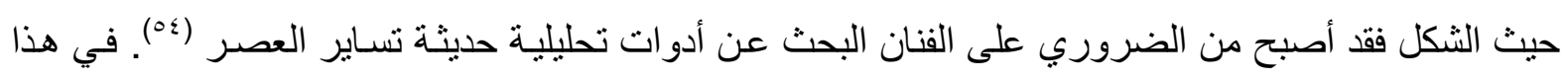
العقد انخرط الفنان العر اقي بمقاومة الأوهام بالوقائع لقد كان جيلاً خضبته الأيام بالدروس القاسية فكانوا يبحثون

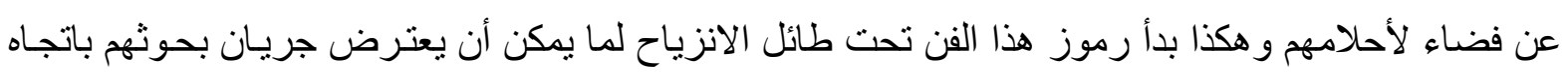

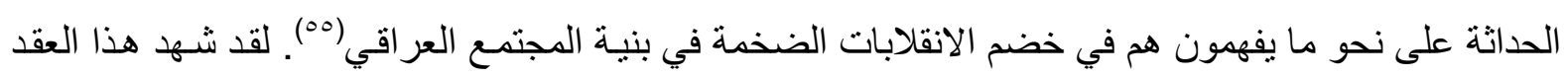
و لادة وتأسيس الكثير من الجماعات الفنية التي استطاعت أن تعيد النظر في بنية العمل الفني شكلا ومضمونا فتمة مهار ات ومواهب عاثتت أعماق المضمون ، وقد امتازت هذه التجارب بـالطموح وبلغت ذروتها في أزمـة

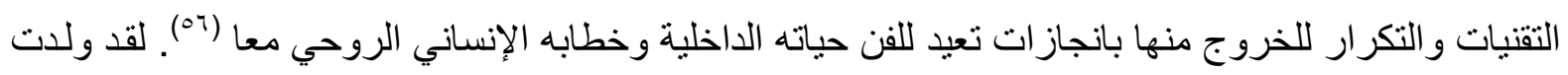
في هذا العقد (جماعة الأربعة) (*) لتحمل مسؤولية جيل لم يزل وقتها يشتغل في الغياب ، و هؤلاء الأربعة جلبوا

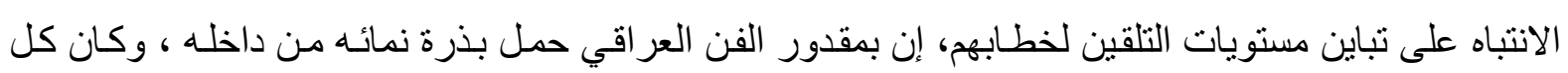
منهم يسعى لاقتر اح وسائل تصويرية تطبع العلاقة مع الذائقة على نحو مفارق , وكان اجتمـاعهم يبشـر بانتصـار روحي على الثكل , والثكل على التزيين، ان هذه الجماعة ترعرعت في أجواء الحرب ومـا بعد الحصسار فلم

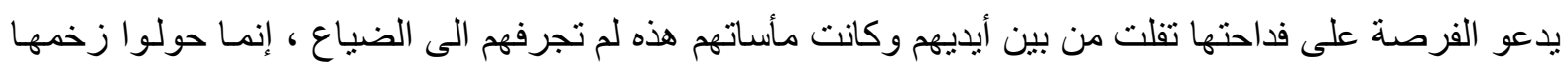

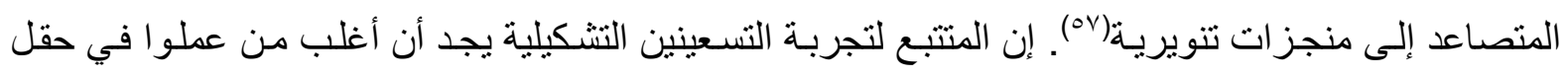
الرسم استطاعو ا تحديد ملامح لوجودهم , وهم يشغلون حيز اً لا يمكن إلا الإشـارة إليه كونـه منجزاً في الحركة التشكيلية العر اقية , وقد بدأوا يقطفون ثمـار تجاربهم ويلقون صدى طيباً بـالرغم من نشتت جهود هذا الجيل ، حيث لا يلتقون إلا بين أوقات متباعدة بمعارض, فمتابعة هذا الجيل صعبة بسبب طبيعة المتغير ات المفاجئة

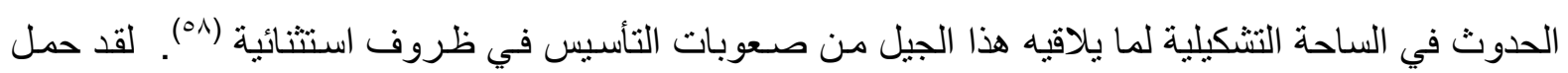
هذا العقد معه الكثير من الهموم و المعاناة نتيجة آثار الحربين وما تلاها من حصسار صـارم أمتد إلى مـا بعد هذا فئه العقد , و الثعور المؤلم بالعزلة و الإحباط لاى الجميع , فقد شملت هذه المعانـاة مختلف شر ائح المجتمع العر اقي 
التي كانت ترزح تحت مختلف صنوف العزلة والقلق والخوف والمرض و العوز والفقر , فآتار هـا غطت جميع

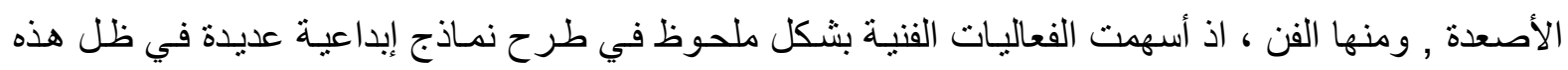
الظروف المعقدة و الاستنتائية, ظهر في هذا العقد فنـانون كـان لـيهم إصـر ار على مو اصـلة التجارب الفنيـة وتقديمها بأساليب جديدة حملت معها سمات المرحلة الراهنة ـ وقد كثف المشروع التسعيني عن ملامح حداثية ذات أثر جلي في خضم التذاخل مع طروحات الثمانيين فقد افرز منجزاً ذا طبيعـة تعدديـة متمركزاً حول هموم عقده , وقد أحاطوا بها ببر اعة حقاً, حتى أنهم زحفوا على الو اجهة بمزيد من التقة و الخطى الر اسخة وبمقدور

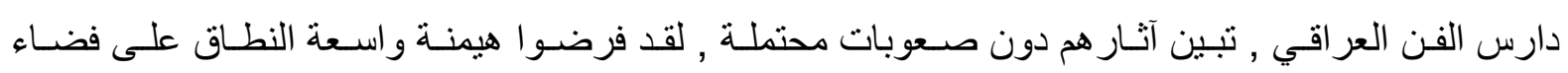

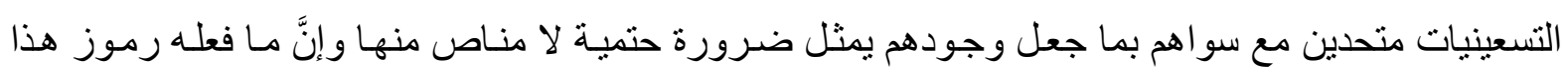
العقد شيء يبعث الثقة بالرسم العر اقي وقدرة على التوليد دون انقطاع و على مدى مئة عام من الكفاحية و الجدل , و التتوع (ه) . ثم اخذ الفن في العراق يتطور والفنان العر اقي اخذ يو اكب الاحداث التي تمر بها البلاد سواء على المستوى السياسي او الاقتصادي او الاجتماعي او الثقافي ، وهو بشكل واخر جعل من نتاجه الفني يتجدد

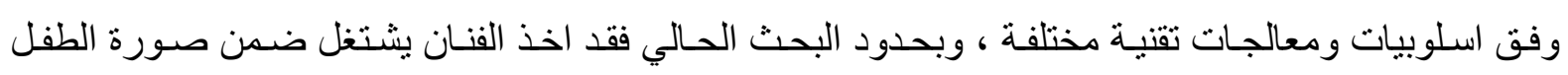

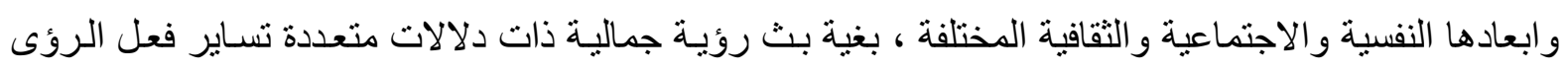
الفنية المتطورة في عالم التشكيل .

لذا يـرى الباحتُان ان الفنـان العر اقي فرض طوقـاً جماليـاً ونفسياً وثقافياً على مجمـل مـا يتعلق بمنجزه

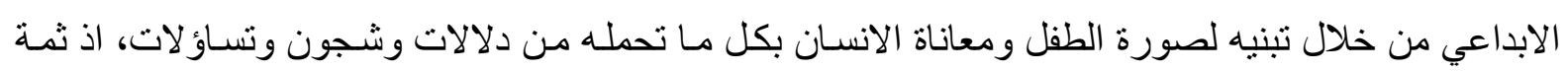
خطاب نفسي كان يحتكم من خلاله الى معالجة قضايا الانسان في مجتمعه الذي يحمل في طياته نو ازع الانسـان

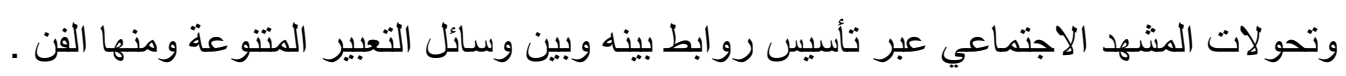
مؤشرات الاطار النظري ا - ان ما يحصل من انتاج فني لدى الفنان اساسه و اقعي وان صورة الطفل هي اصلا موجودة في الواقع المعاش . .

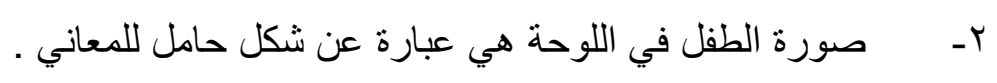
r- صورة الطفل في العمل الفني تحمل دلالات تعبر عن انعكاسات و اقعية .

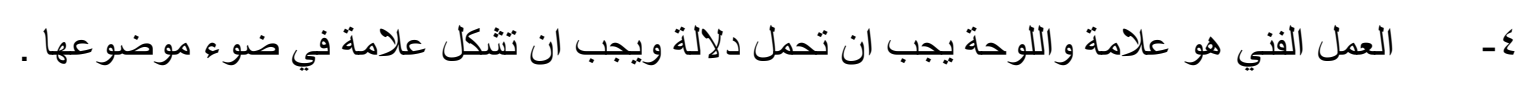

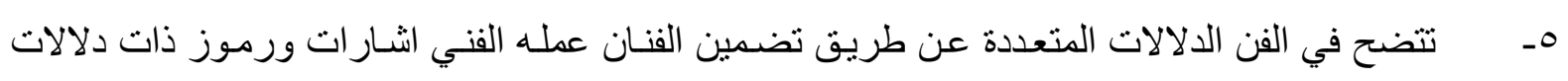
نستدل عليها من خلال قر اءة المنتج الفني . T- ان حقيقة العمل و النشاط الفني عملية انتقاء واعادة تنظيم لتلأك المادة المستمدة من الحياة . V- المادة هي صورة ولكنها لا تصبح صورة فنيـة تتسم بالأصسالة والتفرد الا بعد ان بتناولها الفنان ويعيد تشكيلها وصياغتها منتجا اشكالا فنية جديدة ذات دلالات متعددة . 1- في العمل الفني يظهر الثكل و المضمون في حالة تلاحم ووحدة تجمعهما معا ، فلا يمكن فصل الثنكل

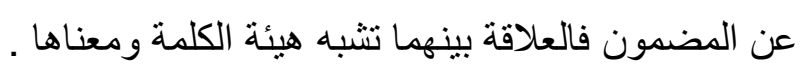




\section{الفصل الثالث- إجراءات البمث}

اولا : مجتمع البحث: بعد الجهد المبذول من البـاحثَين في متابعة المصـادر و الكتب الفنية ذات العلاقة والثبكة المعلوماتية (الانترنيت) ، فضلا عن التواصل مع الفنانين العر اقيين فقد توصلا الى عدد من الاعمـال الفنيـة التي لتي تشتغل ضمن البحث الحالي ، اذ بلغ مجتمع البحث (·r) عملا فنيا . ثانيا : عينة البحث: اختار الباحثان عينة بحثهما البالغة (0) نماذج بصورة قصدية بما يتناسب وطبيعة هدف البحث . ثالثا : منهج البحث : اعتمد الباحثان المنهج الوصفي بأسلوب تحليل المحتوى . رابعا : اداة البحث : اعتمد الباحثان المؤشرات الفلسفية والجمالية والفنية التي انتهى إليها الإطار النظري لتسـهم في أغناء تحليل نماذج عينة البحث وفق الخطوات الآتية :

$$
\text { ا . . وصف عام للعمل الفني (عينة البحث) . }
$$

r. تحديد المنطلقات المعرفية والجمالية و الفلسفية العامة للعينة . ك. بـ ـ تعقب دلالات صورة الطفل وما يرتبط بها من جو انب شكلية ومضـامينية وفق الرؤيـة المعالجاتيـة والتقنية

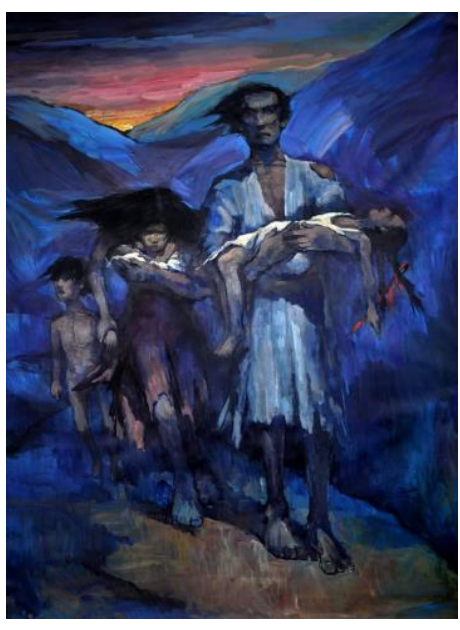

للفنان العر اقي في العمل الفني . خامسا : تحليل عينة البحث :

انموذج (1) اسم الفنان : صفاء السعدون

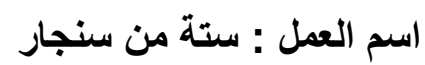

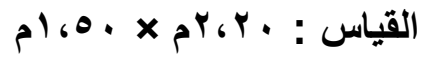
سنة الاتجاز : 19 المادة : اكريليك على كانفاس العائدية : ملكية خاصة بالقنان

يمثل العمل مشهداً لمهجّري مدينة (سنجار) التي تقع شمال الموصل ، اثنـاء دخول داعش الارهابي ، يجسد العمل الفني عائلة مكونة من ستة اثخخاص (الاب والام وثناث اطفال وجنين) ، يسير الاب في المقدمة يحمل طفلة مرتدياً ملابس ممز قة ، وخلفه الام تحمل طفلاً صغير اً بيدها اليسرى وتمسك الطفل الاخر بيدها اليمنى يمشي عارياً وتحمل جنيناً في جوف بطنها ، وهذه العائلة تسير وسط الجبال وهم حفاة ، كما وضع الفنان نوراً في عمق اللوحة للاشارة الى ومضة الامل عند بزوغ الفجر. ان هذا المشهد يحمل جمالية تعبيرية من خـلال توزيع عناصر موضـوعه بطريقة تشير الى المعنى الدلالي الذي يحتضن الموضوع ، سيما في كيفية نتييد البناء التكويني للعمل ، وبحدود البحث الحالي فإن صورة الطفل تجسدت برؤيسة تعبيريـة وجماليـة تنشـ التجسيد الحرفي الاكـاديمي المفعم بـالروح الداخلية للفنـان ، اذ نلحظ ان الفنان اعطى للطفل اهمية في هذا المشهد ، فالطفل ومـا يحمل من براءة وصفاء ونقاء بعيدة عن الوان التعب التب 
و وشاكل الحياة ، نجد الفنان البس الطفلين ثوبـاً ابيض اللون للالالة على بر اعتهم النقيـة ، فكانت الروئية التقنية

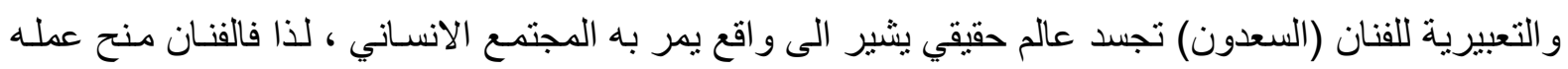

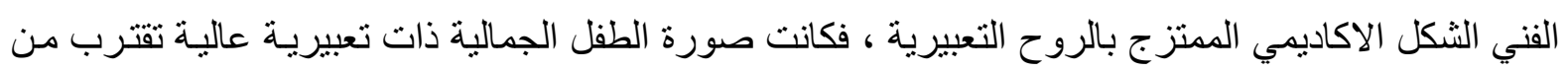
الو اقع وتتثد الحسي والمثالي معاً ، ويعمل على بـث فيوضـات الوجدان ، فالفنان (السعدون) يستقر أ موجوداتهـ

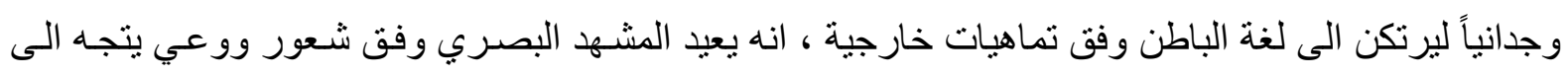

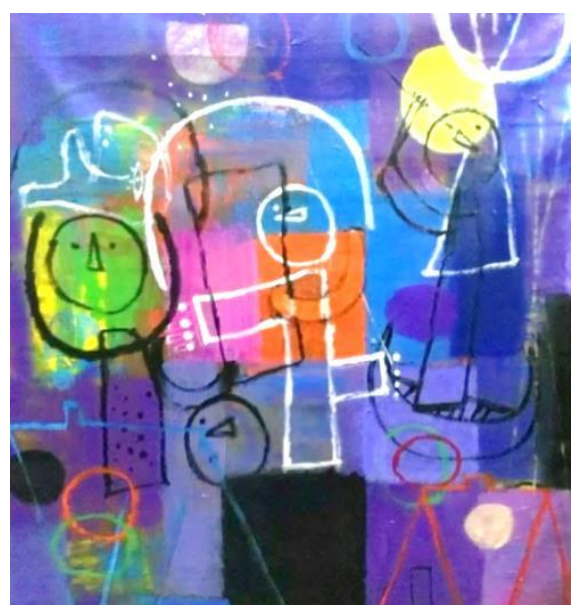
تسجيلية منطقية للمشاهد الخارجية .

(r) (بموذج) اسم الفنان : عاصم عبد الامير اسم العمل : ليلة بكى فيها القمر : عاصم الامير

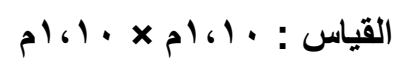

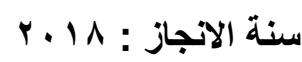
المادة : اكريليك على كانفاس العائدية : ملكية خاصة بالفنان

يجسد هذا المنجز الفني مشهداً جمالياً تتوزع فيه اشكالاً تجريديـة لاطفال وهم يقومون بممارسـات تعبيريـة

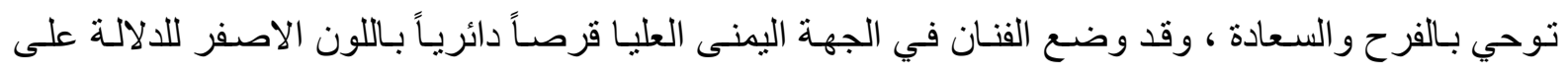
الثمس ، ويتوسط المنجز مربعاً باللون البرتقالي وشكلاً اخر في الجهة اليسرى بـاللون الاخضـر ، و العمل كله

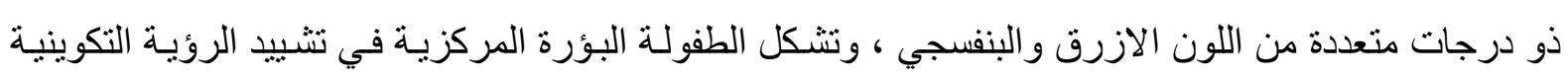
و البنائية للمنجز ، من خلال الخطوط التجريدية الملونة التي تمنح المشاهد رؤية الاشكال الانسانية بروح طفولية ير اد منها بث التعبير العفوي والجمالي للطفولة .

ان المتأمل لهذا المنجز الفني يلحظ قدرة الفنان على تجسيد الروح التعبيرية للطفل ، فما برسمه الطفل بعفويـة

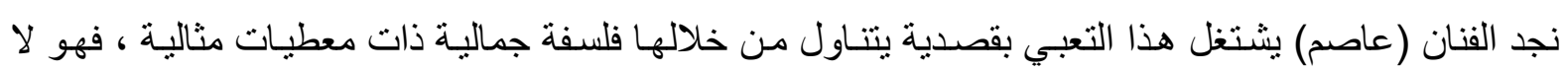
يولي الهية للعالم الحسي بالرغم من تشييد عناصر منجزه من هذا العـالم ، إلا أنه يعمل على ترسيخ منظومـة

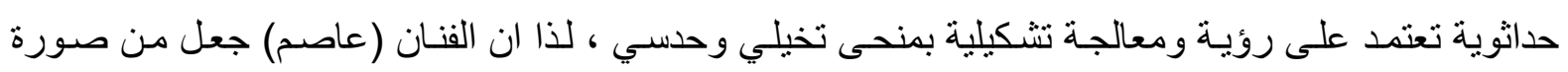
الطفل ذات الخطوط الظاهر اتية تضج بمعاني ودلالات جمالية ، فهي تنشد السعادة عبر تشكيل الخط ذو الطابع

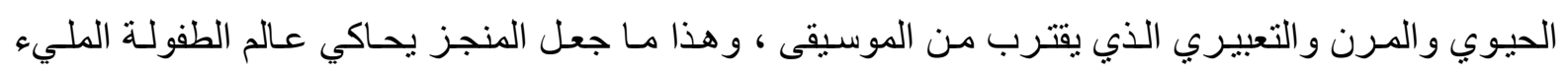
بجمالية الامل و الحياة البعيدة عن ضجيج الحزن و والالام .

ان صـورة الطفل في هذا الخطـاب بمسمياتها الاسلوبية التجريديـة تحمل استطيقا العذوبـة والعفويـة التي لا تخرج عن بساطة الحياة ، انها سيميائية الذات التي تتلاعب مـع الثـعور الداخلي بغية الارتقاء و التسـامي عن عالم الصر اعات المليء بالقبح و الوصول الى عالم النقاء والامل و السعادة . 


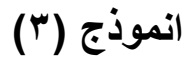

اسم الفنان : فاخر محمد

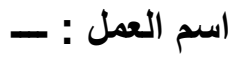

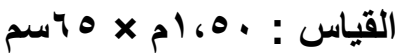

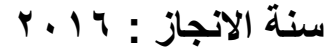

المادة : اكريليك على كاتفاس : الاس

العائدية : ملكية خاصة بالفنان

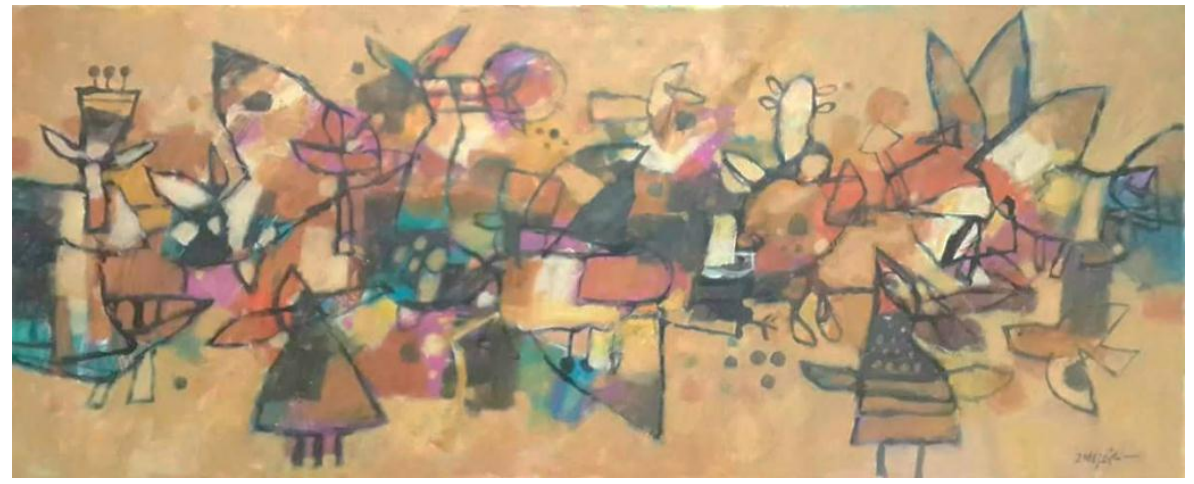

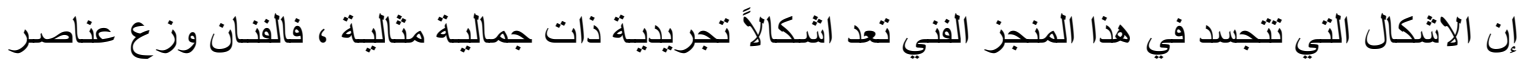

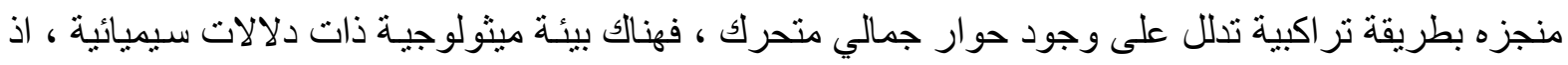

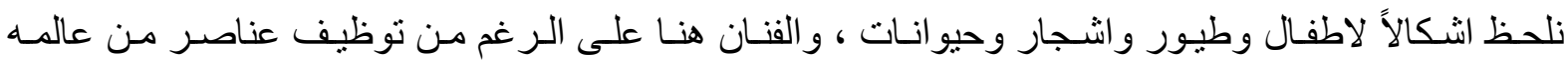

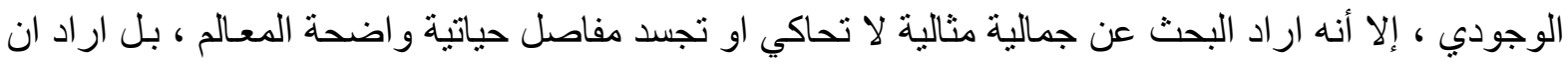
يعمل على تثيبيد رؤية مثالية تغاير المألوف . لئ.

إن صورة الطفل في هذا النجز قد اختزلت نحو التبسيط الذي يحاكي عالم المثل الافلاطوني ، انها الرؤية

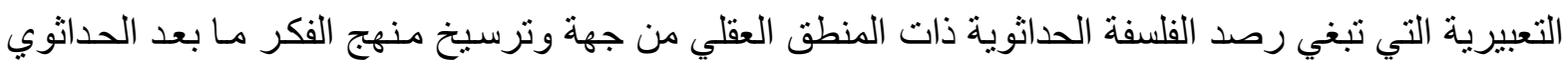

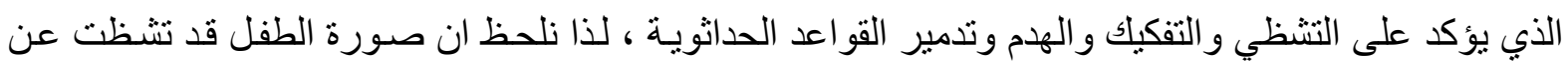

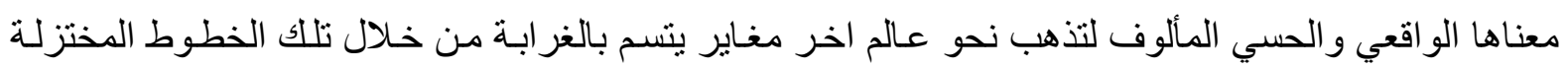
التي اعطت في نهاية الامر شكلاً مبسطاً ذو جمالية ذات فعل روحاني ، الامر الذي يجعل الهشاهد لهذا العمل

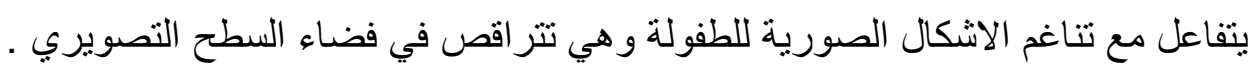

لذا ان صورة الطفل الثكلانية والمضامينية تتجسد عبر الرؤية الجمالية التي اراد الفنان (فاخر محمد) توثيقها

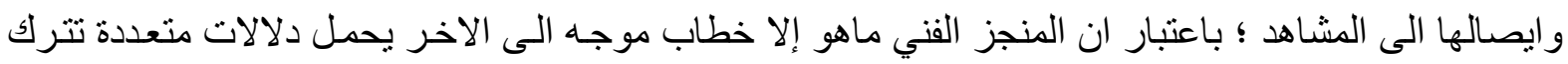

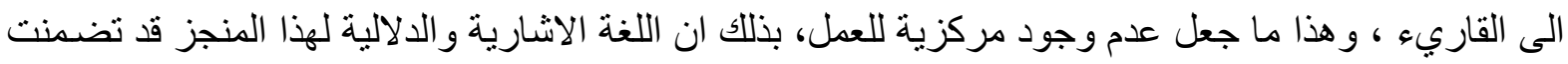

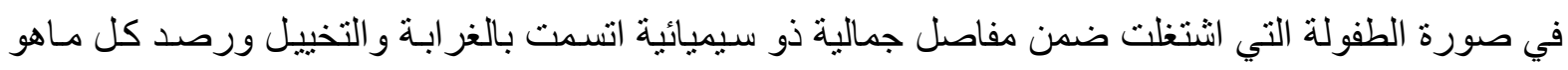
رؤيوي ذاتوي مفعم بالمعاني المنعددة . 


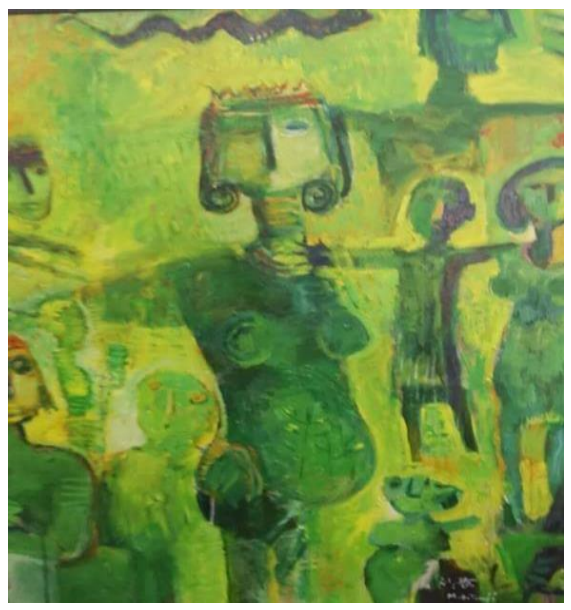

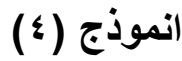

اسم الفنان : مكي عمران اسم العمل : اسطورة وطفولة : اسلة القياس : . . 1 × . .

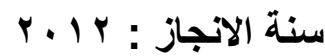
المادة : زيت على كنفاس اله العائدية : مجموعة خاصة للقنان

تتجسد في هذا المنجز الفني صورة الطفولة بشكل مغاير ومختلف عن مشهدية الطفولة الواقعية ، فالفنـان (مكي عمر ان) يثير الى اسطورة ميثولوجية قد ارتسمت في فضـاء السطح التصويري ، فهذا المنجز يتضمن صورة لامر أة استحوذت المركزية وخلفها الى جهة اليمين صورة طفل رافع يديه ، فضلا عن وجود شخصيات اخرى داخل المنجز ، كما اشتغل الفنان على توزيع درجات اللون الاخضر ضمن اجواء منجزه التشكيلي . ان صورة الطفل ترتبط بعالم اسطوري لا يمت بصلة للو اقع ، انمـا ار اد الفنـان ان يشتغل ضمن ممارسـات تخيلية جعلته يخلق نتاجاً فنياً برؤيسة جديدة ، فهو من جهة لا يحاكي عـالم الواقع ومن جهة اخرى يجعل من لن

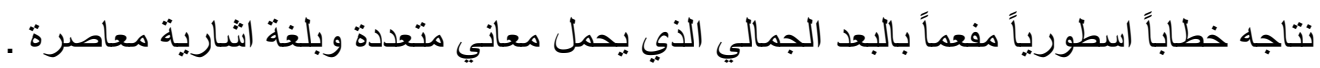
ان الفنان جعل من اللون يحاكي صورة الاسطورة وهي تتماهى معاً بين الثكل والفضـاء ، الامر الذي جعل من النتاج الفني سيما مشهدية الطفل تحاور الفعل الزماني و المكاني وتتمـاهى نحو اللاتتـاهي بفعل ذاتيـة التعبير التي ترصد الحركة الاسطورية ، فالمتأمل لهذه الصورة الطفولية يجد هناك تلاعباً حراً في المعنى الذي ييتغيه الفنان في مقصدية المشهح ، الى الحد الذي يجعل من (الاسطورة والطفولة) تمثل معنى (الامومة) او العلاقة بين الطفل و الأم ، و هي علاقة لامتناهية توحي بالامل و الحنان و السعادة الابدية ، و هذا ما جعل الفنان يغطي منجزه الفني باللون الاخضر الذي يشير الى دلالات السعادة والامل في الحياة ، فالفنان يجسد صورة عائلة اسطورية لها ممارسات جمالية ترتقي نحو عالم خاص بذاته لا بحاكي أي عالم خارجي سوى عالم المنجز ذاته .

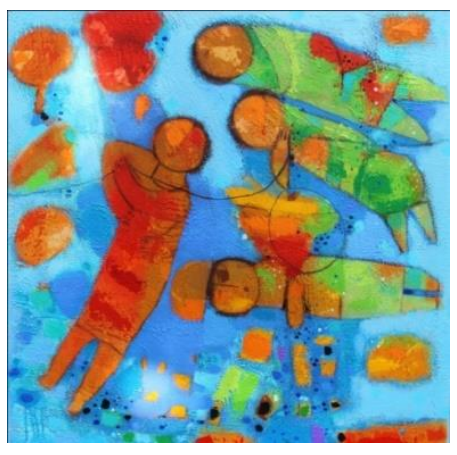

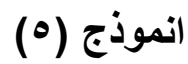
اسم القنان : هاشم حنون

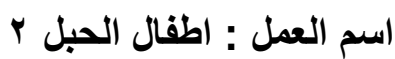

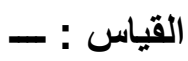

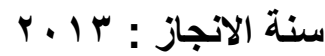
المادة : اكريليك على كانفاس

MAYBERRY FINE ART, WINNIPEG, MANITOBA : العائدية 
يعبّر هذا المشـهد البصـري عن رؤيـة تعبيريـة جماليـة يكون فيـه الطفل البؤرة المركزيـة في تشيبيد تلك

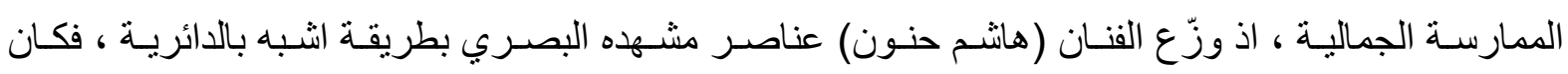
الاطفال ينتشرون في فضـاء اللوحة وهم يمسكون حبلاً اسود اللون ، وكأن الفنـان يريد القول ان هناك حبلاً

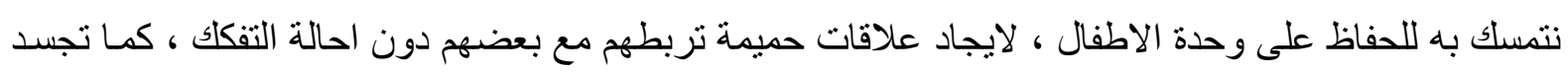

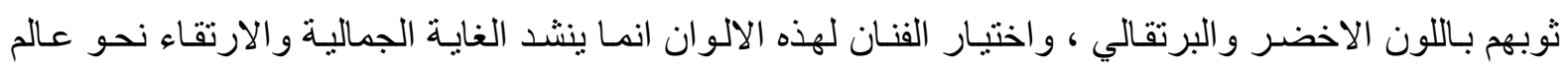
السعادة و الاستقر ار النفسي للاطفال ؛ باعتبار انهم يقومون بممارسـات طقوسية ترتبط بعمر هم الزمني ، إلا أن الفنان ومن خلال رؤيته المعالجاتية والتقنية لم يذهب الى تجسيد هذا الو اقع بصورة كلاسيكية انمـا اخذ ينتهج منهجاً حداثوياً معاصراً يعتمد على التجريد و التبسيط والاختز ال بغية اظهار صورة الطفل بطريقة جديدة تتلائم

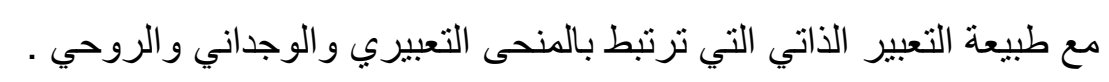

ان الغاية التي يقصدها الفنان في هذا المشهد تتعدى حدود الرؤية الاحادية المعنى ، فهو يترك للقاريء حريـة التمعّن و التأمل ومن ثم التأويل الذي يتجه نحو وضع معاني ربما تختلف عن المعنى المقصود للى الفنان ، لذا فالجانب الجمالي في صورة الطفل تختلف من واحد الى اخر ، بحسب الرؤية المكانية والموضعية التي تجسدت في فضاء اللوحة ، فالفنان يولي اهمية الى منح المنجز الفني رؤية انشائية وبناء تكويني متجدد ومتحرك يتفاعل بين الخط والثكل و اللون مـع الفضـاء المحيط ، الى جانب ذلك نلحظ ان هنـاك سر و اضـح في وجوه الاطفال

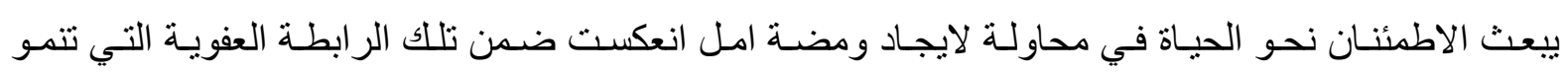
ونتطور لاحقاً.

بـذلك ان صـورة الطفل في هذا المشـهـ الجمـالي حققت رؤيسة مثاليـة متعاليـة استتطقت مـا ورائيـة الحسي المحدود، اذ لا يمنح الفنان أي اهتمام لواقع كلاسيكي بقدر ما يريد بث رؤيته الجماليـة عبر التبسيط والاختز ال الذي يثير الى دلالات مضامينية متعددة لا تقف عند حد .

النصل البرابع

اولا : النتائج

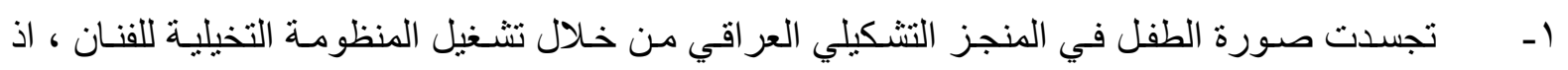

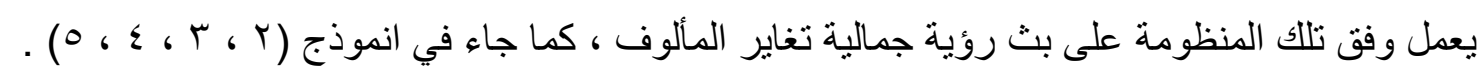

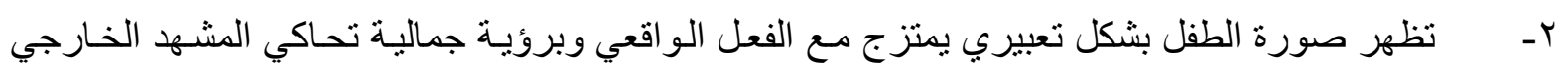
كما في انموذج ( ) (1) - (1)

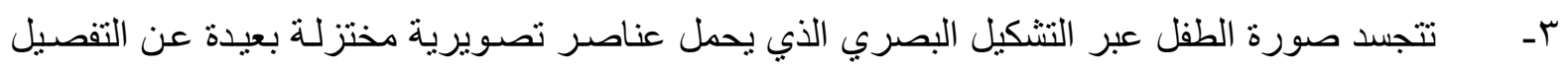
الاكاديمي والو اقعي ، فيلجأ الفنان الى التجريد بـالخط و الثنكل ، فضـلا عن التبسيط في الالوان ، كمـا جاء في

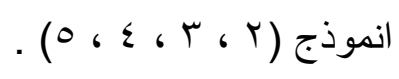


ع- - تظهر جمالية صورة الطفل في التشكيل العراقي من خلال توثيق الفنان لمر احل عمريـة طفوليـة ترتبط بالبيئة الاجتماعية ومدى علاقة الطفل بروح العائلة الواحدة ، بغية تحقيق الرؤيسة الجمالية التي تنشد المثنالي ،

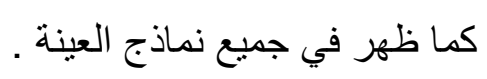

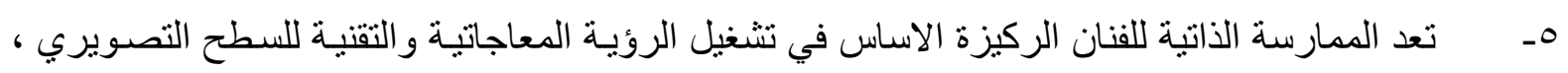
لذا تتماهى صورة الطفل مع البنية الدالة التي تحتضن فضاء المنجز الفني ، كما جاء في جميع نماذج العينة . آ- تمتزج الرؤية الجمالية في صورة الطفل مع الممارسة الطقوسية الاسطورية منها و الو اقعية الحياتية من

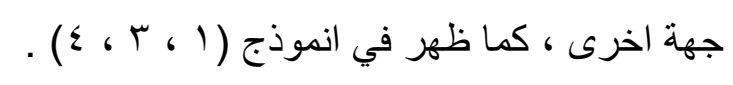

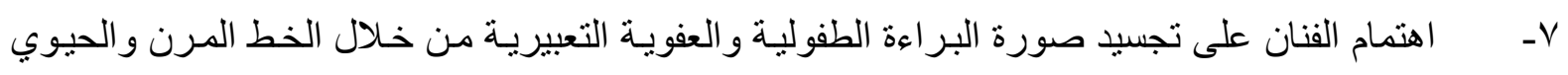

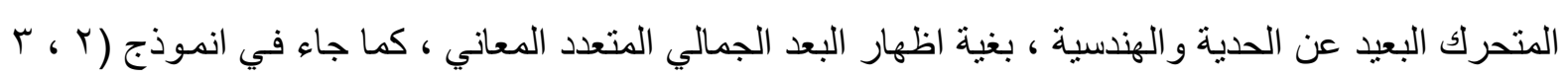
. (0 6 $\leqslant$ ، ثانيا : الاستتناجات

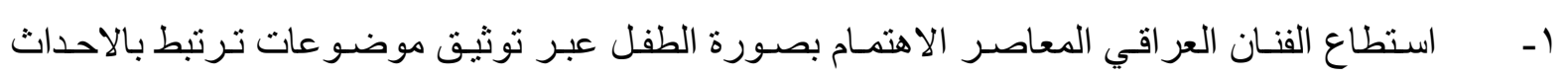
الو اقعية والمشاهد الحياتية المتعددة .

r- تمكن الفنان عبر رؤيتهـ المعاجاتيـة والتقنية ابراز جوانب جماليـة لصورة الطفل تغاير المألوف ، من خلال فعل التجريد الذي يحاكي التبسيط والاختز ال في الاشكال .

بـ - ركّز الفنان على بث الرؤية الجمالية لصورة الطفل عبر التعبير الوجداني و الداخلي للفنان ، وهو بشكل واخر ير اد منه اظهار البعد الجمالي الذي يتحقق بفعل الممارسات الطقوسية للطفولة .

ع- الفنان العر اقي المعاصر يولي اهمية في تشكيله البصري على بث سمات وخصـائص صسورة الطفل

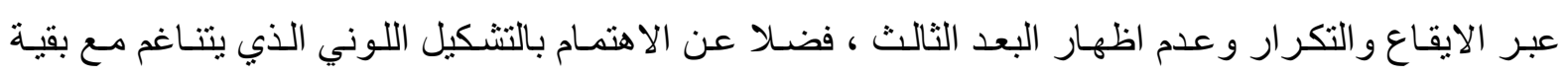
العناصر الخطية والثكلية . ثالثا. التوصيات: يوصي الباحثان بالاتي : ا - نشر الدر اسات الأكاديمية و العلمية الحديثة التي تخص صورة الطفل ؛ بوصفها تشكل جزء مهم في النشكيل المعاصر . n

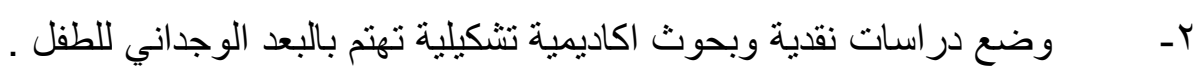
رابعاً : المقترحات استكمالاً لمتطلبات البحث الحالي يقترح الباحثان إجر اء الدراسات الآتية : 1 - الثابت و المتحرك في صورة الطفل . r- اثر نظرية الجشطالت في رسوم الاطفال . 


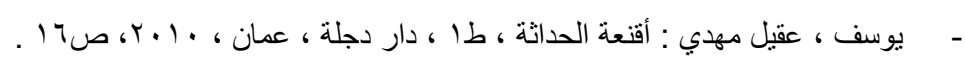

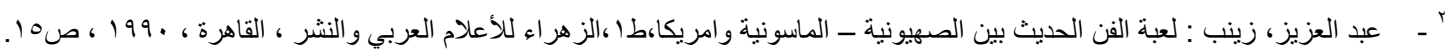

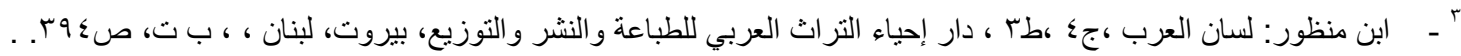

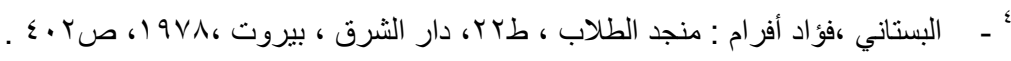

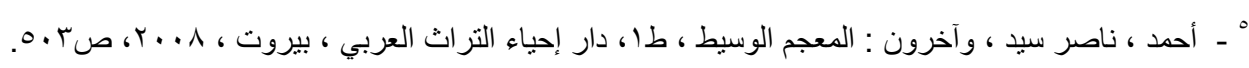

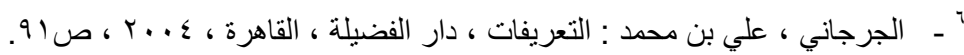

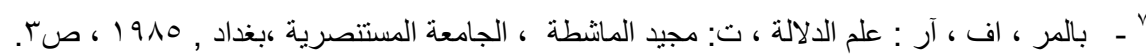

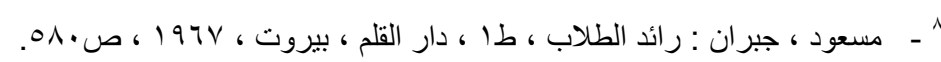

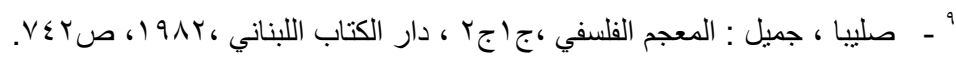

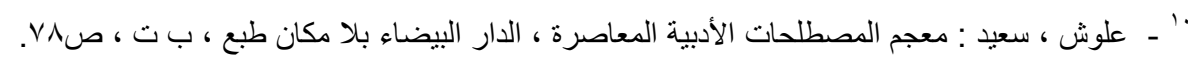

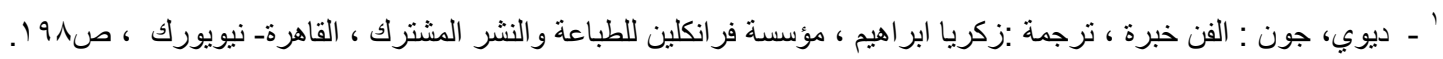

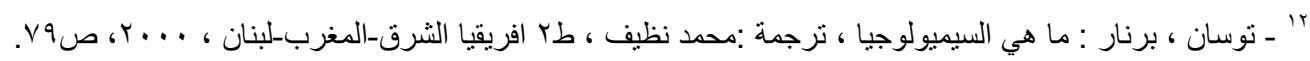

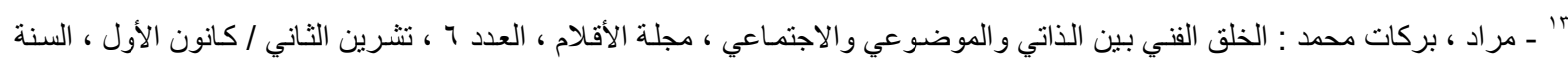

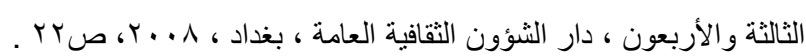

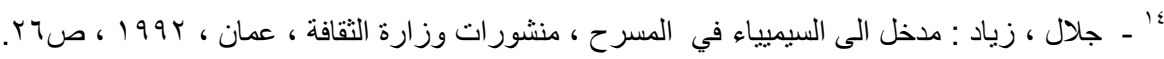

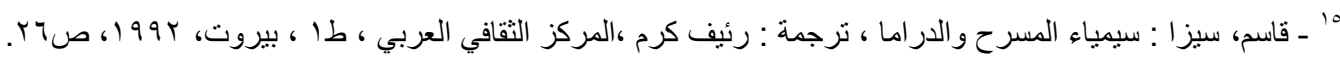

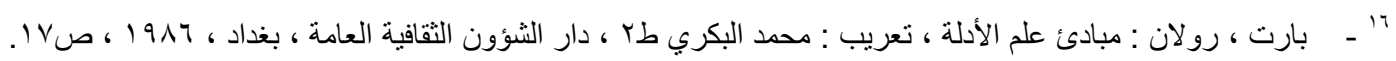

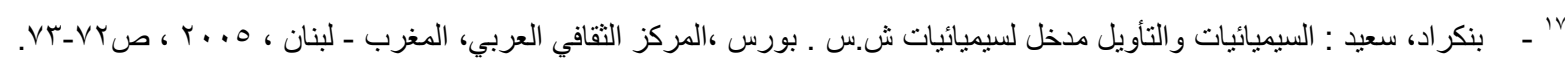

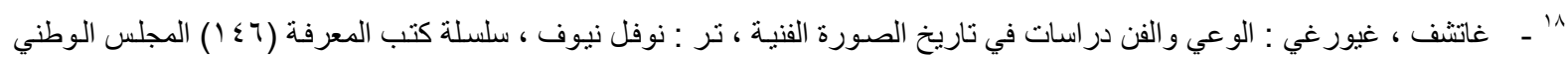

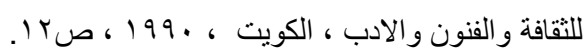

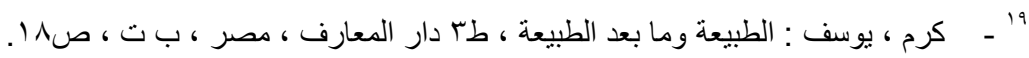

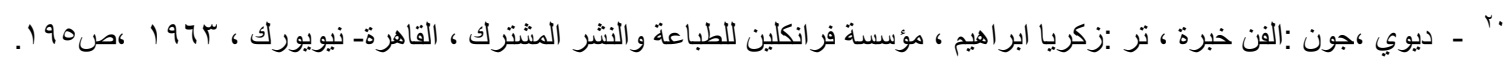

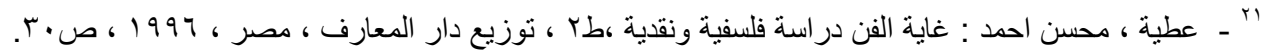

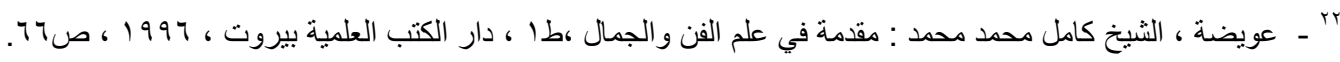

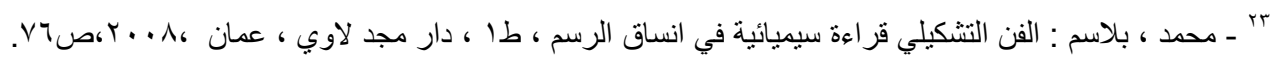

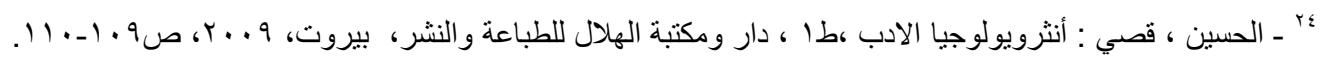

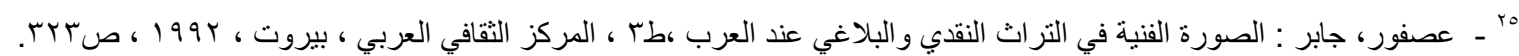

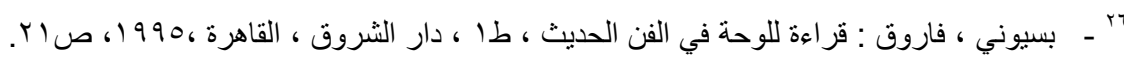

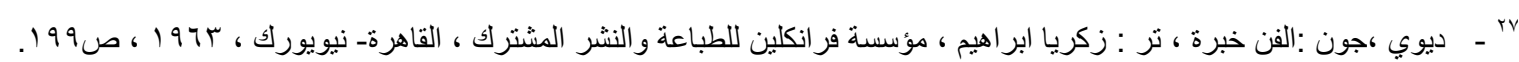

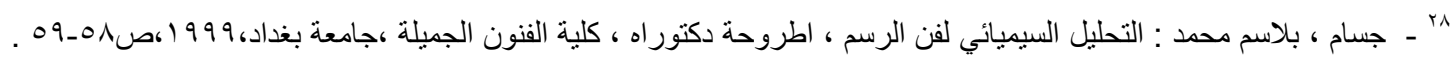

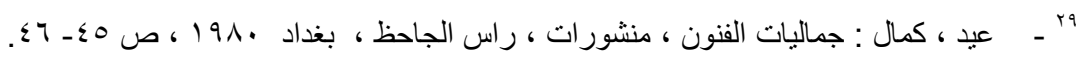

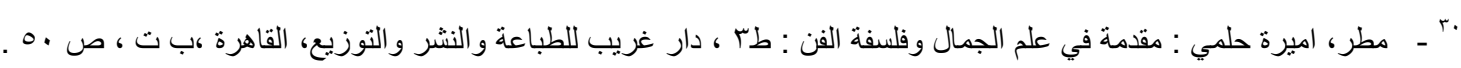

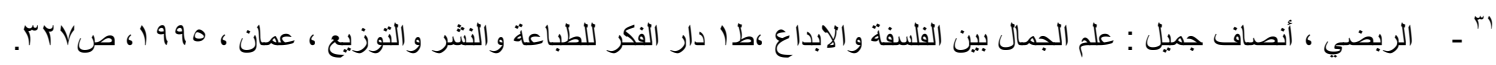

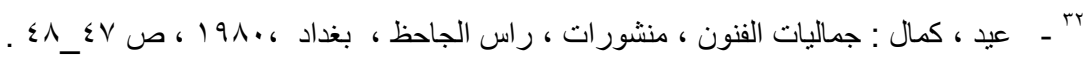

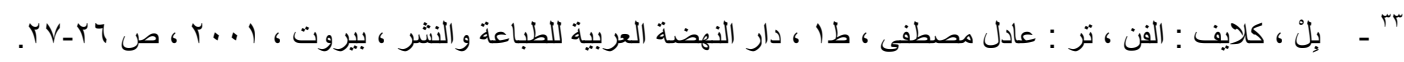

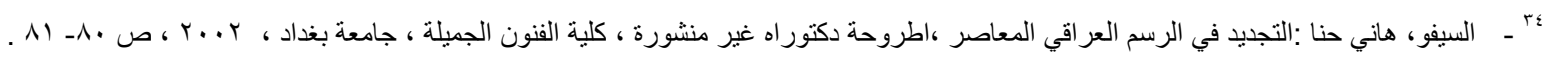

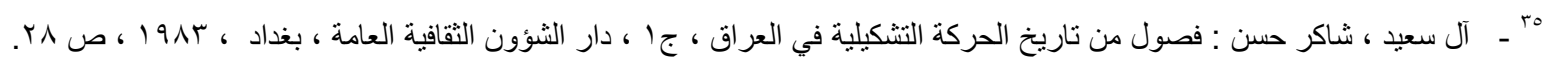

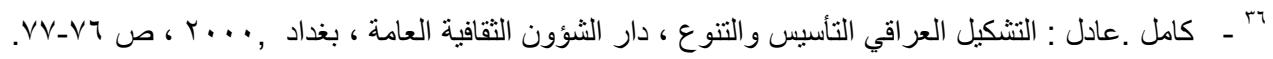


* تأسست بيغداد مطلع ( (1 9 ) ) بمبادرة من أكرم شكري وكريم مجيد وعطا صبري وشوكت سليمان وانضم إليهم العديد من الرسامين الثباب

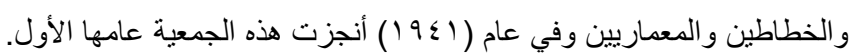

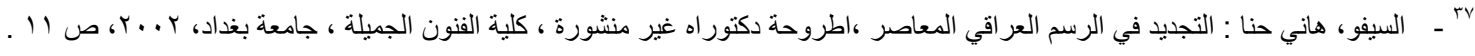

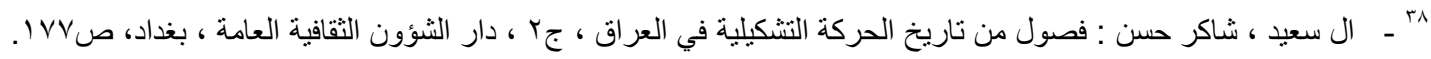

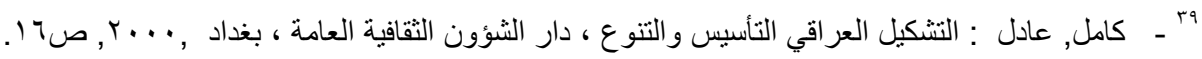

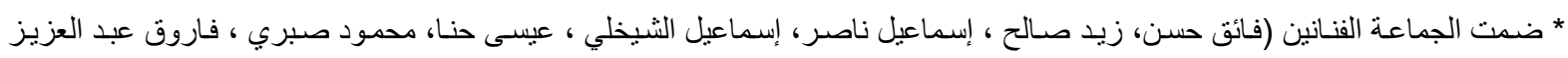

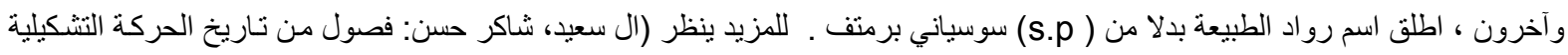

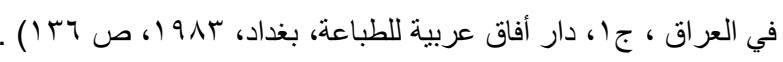

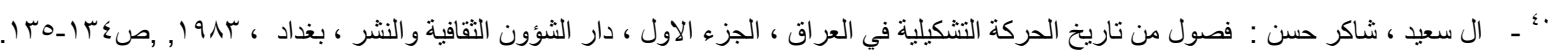

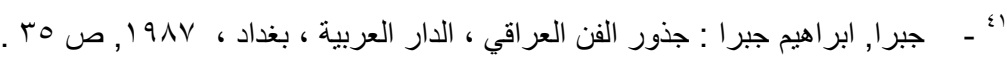

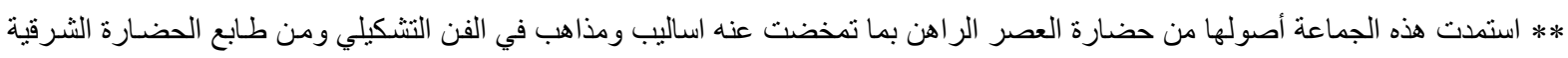
الفذ , وتز عمها الفنان (جواد سليم) وضمت كلاً من (شاكر حسن آل سعيد , محمد الحسيني , جبر ا إبراهيم جبرا , قحطان عبد الله , نزيهة سليم ,

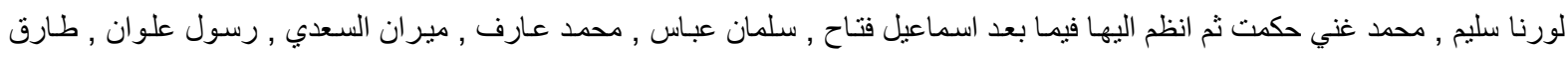
مظلوم , فؤاد جهاد , محمود صبري , خضبر الثكرجي , كانثي رور , علي الثعلان , خالد الرحال , بوعوض بابونيان الثيان , نزار علي جودة , ابر اهيم العبدلي , ثريا نواب , إحسان الملائكة, خليل الورد , عبد الرحمن الكيلاني , للمزيد ينظر : ( آل سعيد شـاكر حسن : البيانات الفنية في

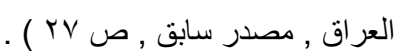

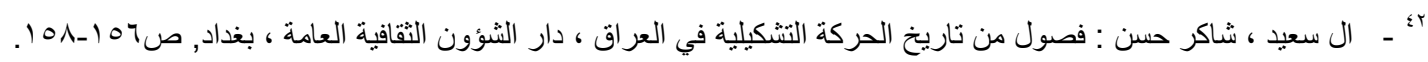

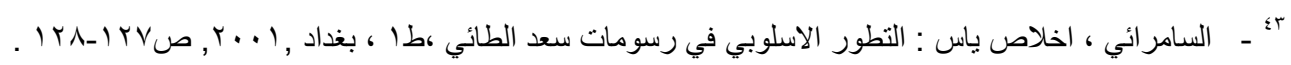

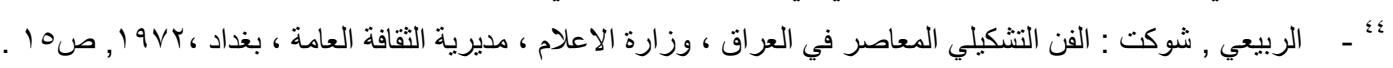

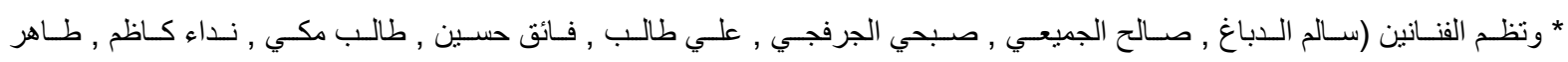

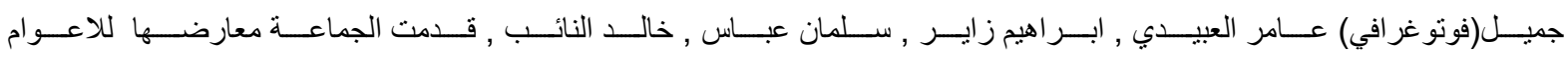

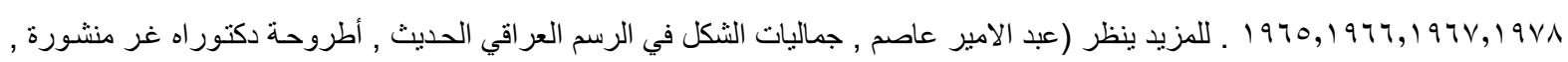

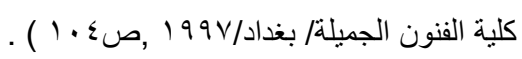

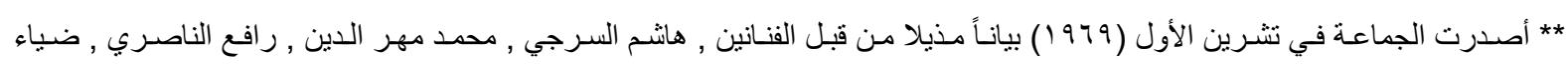

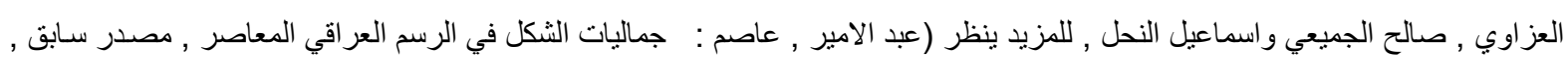
ص ص $1 \cdot(1)$ ه؛ - عبد الامير، عاصم عبد الامير : جماليات الثكل في الرسم العر اقي الحديث ، اطروحة دكتور اه غير منشورة ،كلية الفنون الجميلة ، بغداد .1. 1 ص $199 \mathrm{~V}$,

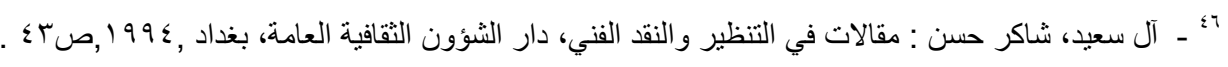

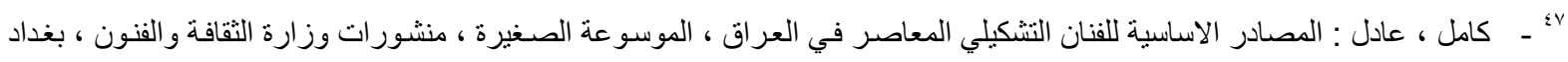

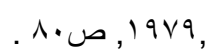

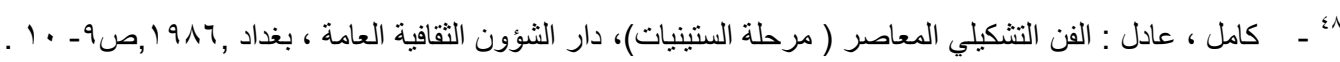

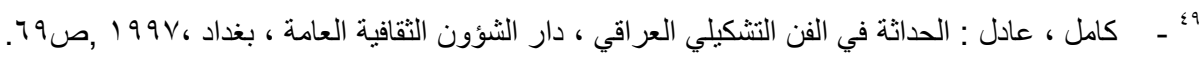

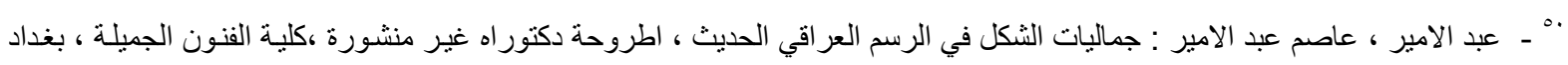

. $111199 \mathrm{~V}$,

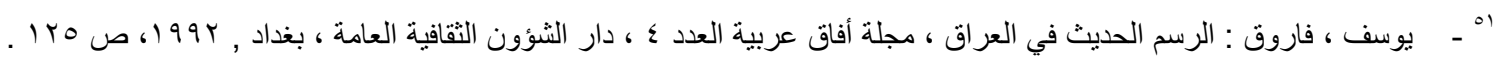

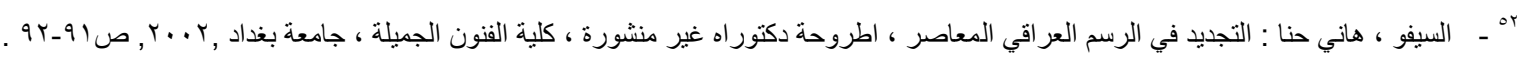

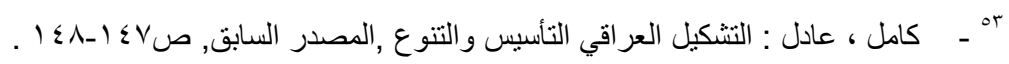

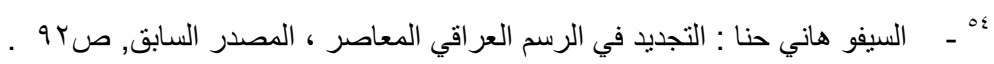

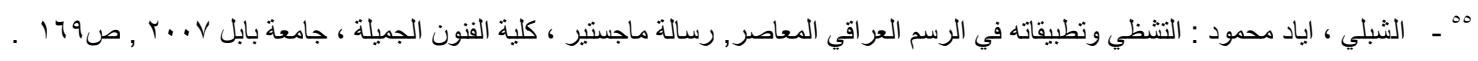




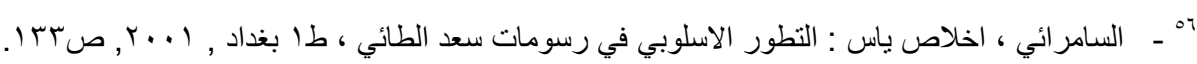

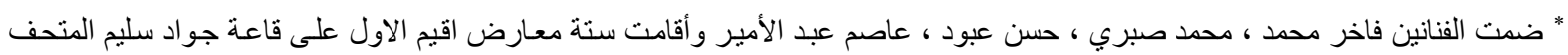

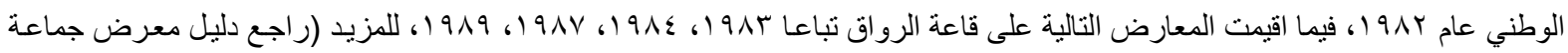

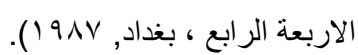

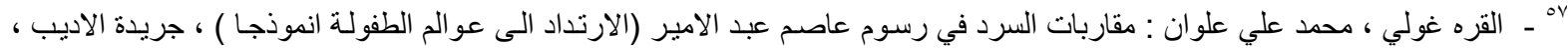

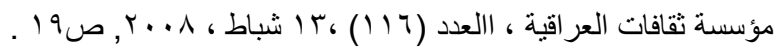

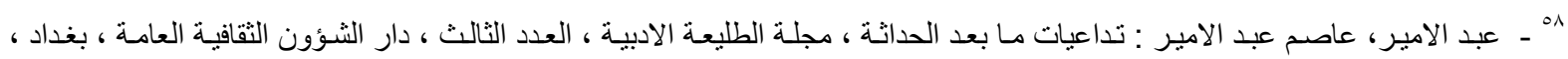
. 17,1999

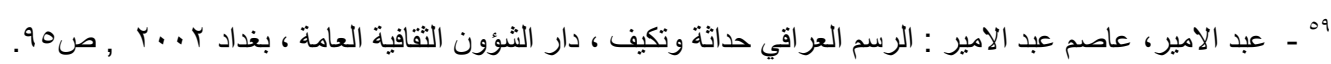

\section{رإl|}

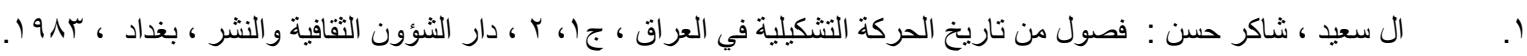

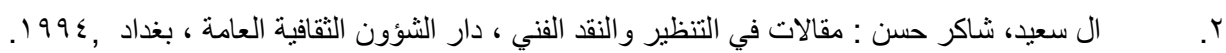

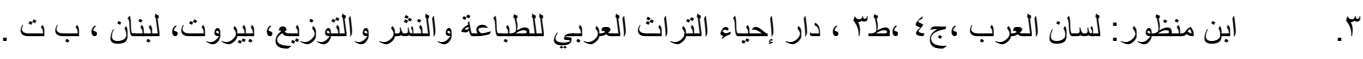

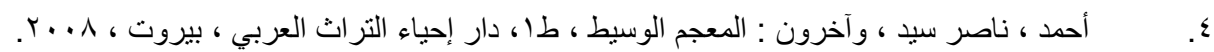

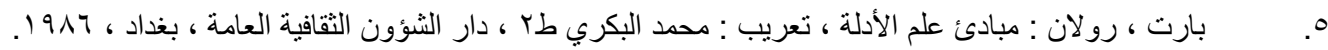

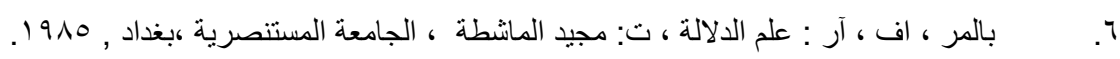

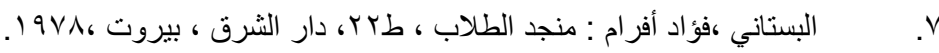

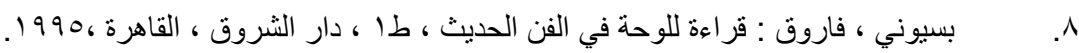

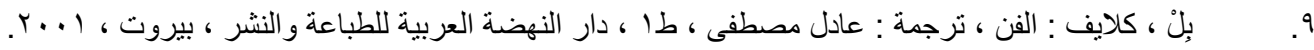

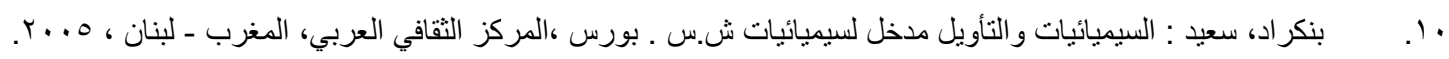

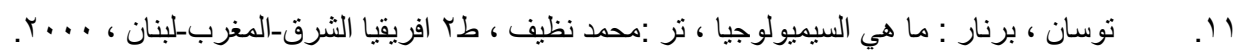

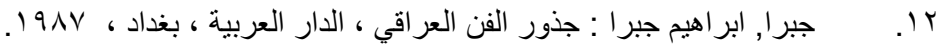

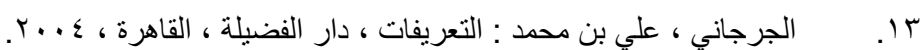

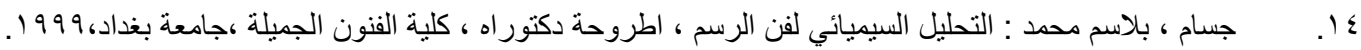

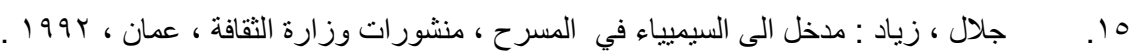

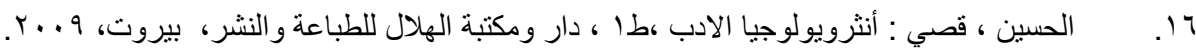

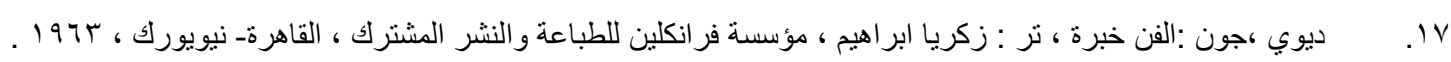

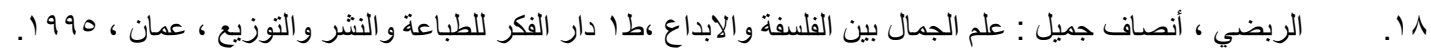

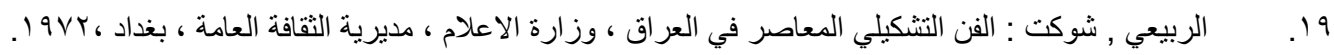

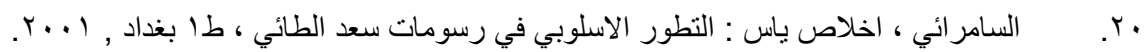

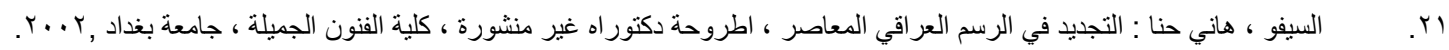

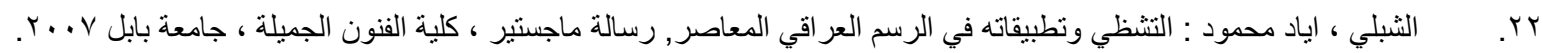

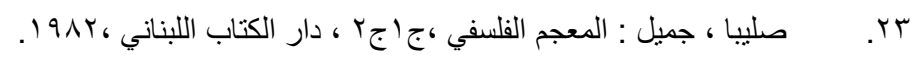

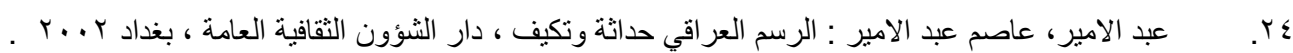

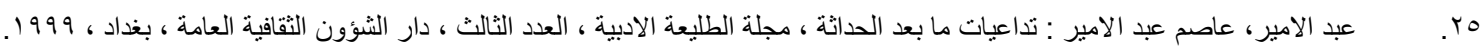

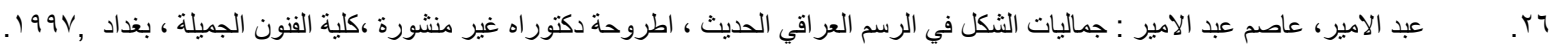

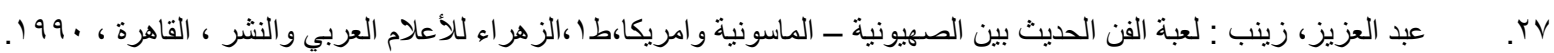

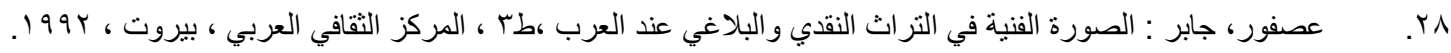

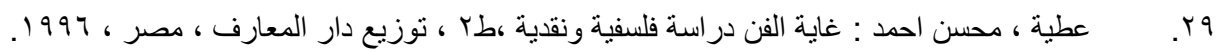


•r. . علوش ، سعيد : معجم المصطلحات الأدبية المعاصرة ، الدار البيضاء بلا مكان طبع ، ب ت .

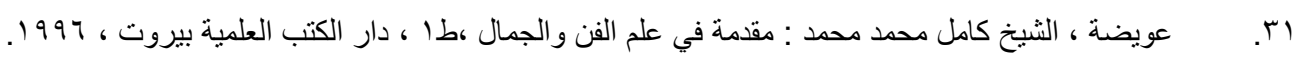

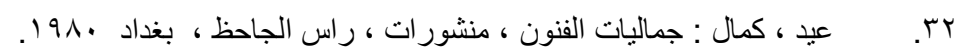

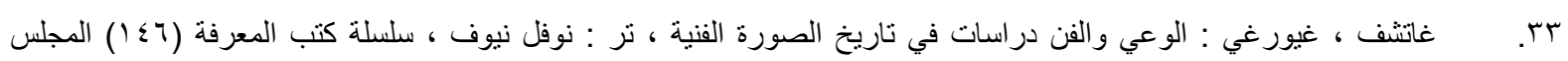

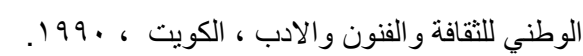

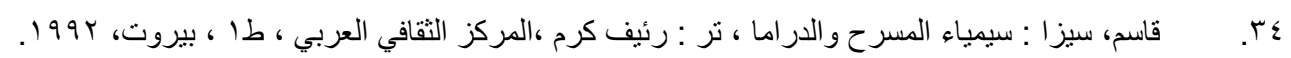

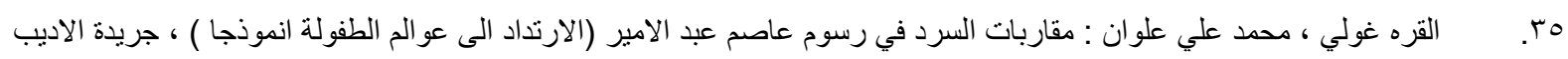

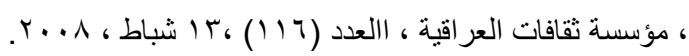

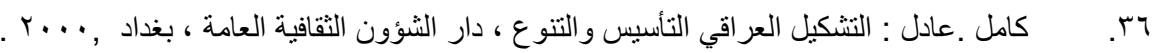

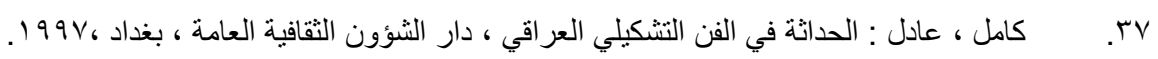

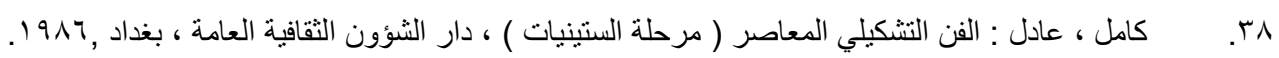

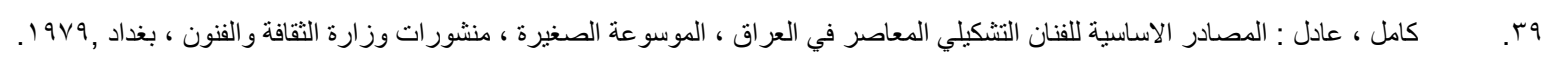

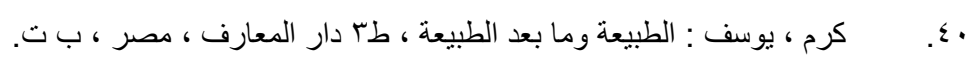

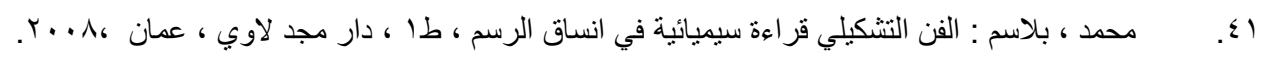

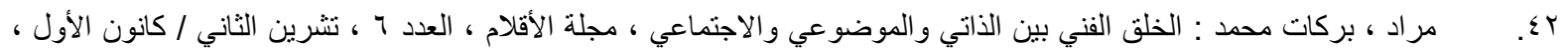

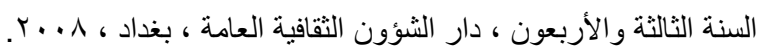

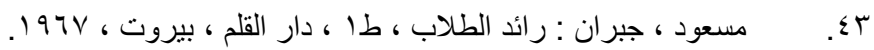

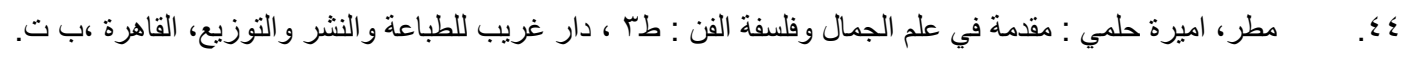

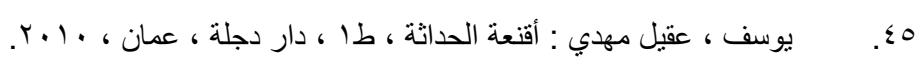

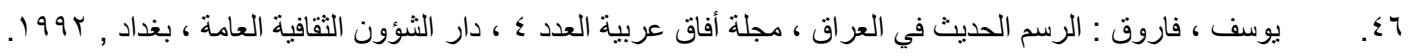

